\title{
Presynaptic Gating of Postsynaptically Expressed Plasticity at Mature Thalamocortical Synapses
}

\author{
Jay A. Blundon, ${ }^{\star}$ Ildar T. Bayazitov, ${ }^{\star}$ and Stanislav S. Zakharenko \\ Department of Developmental Neurobiology, St. Jude Children's Research Hospital, Memphis, Tennessee 38105-3678
}

\begin{abstract}
Thalamocortical (TC) projections provide the major pathway for ascending sensory information to the mammalian neocortex. Arrays of these projections form synaptic inputs on thalamorecipient neurons, thus contributing to the formation of receptive fields (RFs) in sensory cortices. Experience-dependent plasticity of RFs persists throughout an organism's life span but in adults requires activation of cholinergic inputs to the cortex. In contrast, synaptic plasticity at TC projections is limited to the early postnatal period. This disconnect led to the widespread belief that TC synapses are the principal site of RF plasticity only in neonatal sensory cortices, but that they lose this plasticity upon maturation. Here, we tested an alternative hypothesis that mature TC projections do not lose synaptic plasticity but rather acquire gating mechanisms that prevent the induction of synaptic plasticity. Using whole-cell recordings and direct measures of postsynaptic and presynaptic activity (two-photon glutamate uncaging and two-photon imaging of the FM 1-43 assay, respectively) at individual synapses in acute mouse brain slices that contain the auditory thalamus and cortex, we determined that long-term depression (LTD) persists at mature TC synapses but is gated presynaptically. Cholinergic activation releases presynaptic gating through $M_{1}$ muscarinic receptors that downregulate adenosine inhibition of neurotransmitter release acting through $A_{1}$ adenosine receptors. Once presynaptic gating is released, mature TC synapses can express LTD postsynaptically through group I metabotropic glutamate receptors. These results indicate that synaptic plasticity at TC synapses is preserved throughout the life span and, therefore, may be a cellular substrate of RF plasticity in both neonate and mature animals.
\end{abstract}

\section{Introduction}

Cortical receptive fields (RFs) are formed by organized arrays of thalamocortical (TC) afferents projecting onto neurons in thalamorecipient layers of the cortex (Buonomano and Merzenich, 1998; Feldman and Brecht, 2005; Hensch, 2005; Liu et al., 2007). Sensory experience alters RFs in sensory cortices, and this RF plasticity is thought to underlie sensory memory (Hubel and Wiesel, 1970; Gilbert, 1998; Weinberger, 2007a). The cellular and molecular mechanisms underlying RF plasticity are not well understood. Long-term synaptic plasticity at TC synapses is thought to be a cellular mechanism that contributes to RF plasticity and sensory memories (Crair and Malenka, 1995; Feldman et al., 1999; Fox, 2002; Feldman and Brecht, 2005). This theory is currently challenged by a disconnect between the age dependency of TC synaptic plasticity and that of RF plasticity.

\footnotetext{
Received June 27, 2011; revised Aug. 30, 2011; accepted Sept. 1, 2011.

Author contributions: J.A.B. and S.S.Z. designed research; J.A.B. and I.T.B. performed research; J.A.B., I.T.B., and S.S.Z. analyzed data; J.A.B. and S.S.Z. wrote the paper.

This work was supported in part by National Institute of Mental Health Grant R01 MH079079 and the American Lebanese Syrian Associated Charities. The funding sources had no role in study design, data collection and analysis, decision to publish, or preparation of this manuscript. We thank Drs. Bertil Fredholm (Karolinska Institute, Stockholm, Sweden) and MarkZylka (University of North Carolina, Chapel Hill, Chapel Hill, NC) for providing $\mathrm{A}_{1} \mathrm{R}^{-/-}$mice and Angela McArthur for editing this manuscript.

*J.A.B. and I.T.B. contributed equally to this work.

Correspondence should be addressed to Dr. Stanislav Zakharenko, Department of Developmental Neurobiology, MS 323, St. Jude Children's Research Hospital, 262 Danny Thomas Place, Memphis, TN 38105-3678. E-mail: stanislav.zakharenko@stjude.org.

DOI:10.1523/JNEUROSCI.3281-11.2011

Copyright $\odot 2011$ the authors $\quad 0270-6474 / 11 / 3116012-14 \$ 15.00 / 0$
}

RF plasticity can be induced in sensory cortices throughout the life span, although there are differences in how RF plasticity can be induced in young and adult animals. For instance, in the auditory cortex $(\mathrm{ACx})$ of young animals, RF plasticity can be induced by enriching the environment with a single acoustic frequency (Zhang et al., 2001; de Villers-Sidani et al., 2007; Dorrn et al., 2010). However, in mature animals, RF plasticity can be induced in the ACx only when the acoustic stimulus is behaviorally relevant (Keuroghlian and Knudsen, 2007) or is paired with the activation of sources or circuits of modulatory inputs (Bakin and Weinberger, 1996; Kilgard and Merzenich, 1998a; Ma and Suga, 2005), suggesting that RF plasticity in mature animals is gated by modulatory circuits. In contrast, long-term plasticity at TC synapses can be induced in brain slices from animals only during an early critical period that in rodents occurs during the first few postnatal days (Crair and Malenka, 1995; Isaac et al., 1997; Feldman et al., 1998; Foeller and Feldman, 2004; Daw et al., 2007; Jiang et al., 2007). These findings led to the notion that, upon maturation, long-term plasticity at TC synapses is lost, and the cellular substrate for RF plasticity shifts to other synapses (Foeller and Feldman, 2004; Feldman and Brecht, 2005).

Here, we tested an alternative hypothesis that long-term plasticity of TC synapses is not eliminated upon maturation but rather, similar to that of RFs in vivo, acquires gating mechanisms that prevent plasticity. To test this hypothesis, we used whole-cell recordings, two-photon glutamate uncaging (TGU), and twophoton imaging of presynaptic function to study long-term depression (LTD), a major form of long-term synaptic plasticity, at TC synapses of mice that had matured beyond the critical period. 
We determined that LTD persists at mature TC synapses but is gated by presynaptic mechanisms. Release of these gating mechanisms occurs through activation of presynaptic $\mathrm{M}_{1}$ muscarinic receptors $\left(M_{1} R s\right)$ that increase sustainability of neurotransmitter release at thalamic afferents via downregulation of $A_{1}$ adenosine receptor $\left(A_{1} R\right)$-dependent mechanisms. Release of presynaptic gating mechanisms thereby allows mature TC synapses to undergo LTD that is expressed postsynaptically and depends on group I metabotropic glutamate receptors (mGluRs).

\section{Materials and Methods}

Animals and agents. Mature male C57BL/6J mice (P35-P42; The Jackson Laboratory) or mature $\mathrm{A}_{1} \mathrm{R}^{-1-}$ mice (backcrossed to the C57BL/6J genetic background for at least five generations) of both sexes were used in all experiments. The generation and genotyping of $A_{1} R^{-1-}$ mice have been reported previously (Johansson et al., 2001). The care and use of animals were reviewed and approved by the Institutional Animal Care and Use Committee of St. Jude Children's Research Hospital. All drugs were purchased from Tocris Bioscience, except $\alpha \beta$-methylene-ADP ( $\alpha \beta$-mADP), which was purchased from Sigma-Aldrich.

Brain slice preparation. Acute primary TC slices $(400 \mu \mathrm{m})$ containing the ACx and portions of the ventral part of the medial geniculate nuclei (MGv) of the thalamus were prepared as previously described (Cruikshank et al., 2002; Richardson et al., 2009). Briefly, mouse brains were quickly removed and placed in cold $\left(4^{\circ} \mathrm{C}\right)$ dissecting artificial CSF (ACSF) containing $125 \mathrm{~mm}$ choline-Cl, $2.5 \mathrm{~mm} \mathrm{KCl}, 0.4 \mathrm{~mm} \mathrm{CaCl}_{2}, 6 \mathrm{~mm}$ $\mathrm{MgCl}_{2}, 1.25 \mathrm{~mm} \mathrm{NaH}_{2} \mathrm{PO}_{4}, 26 \mathrm{~mm} \mathrm{NaHCO}_{3}$, and $20 \mathrm{~mm}$ glucose (300310 mOsm), with $95 \% \mathrm{O}_{2} / 5 \% \mathrm{CO}_{2}$. Primary TC slices were obtained from the left hemisphere by using a slicing angle of $15^{\circ}$. After a $1 \mathrm{~h}$ incubation in ACSF [ $125 \mathrm{~mm} \mathrm{NaCl}, 2.5 \mathrm{~mm} \mathrm{KCl}, 2 \mathrm{~mm} \mathrm{CaCl}_{2}, 2 \mathrm{~mm}$ $\mathrm{MgCl}_{2}, 1.25 \mathrm{~mm} \mathrm{NaH}_{2} \mathrm{PO}_{4}, 26 \mathrm{~mm} \mathrm{NaHCO}, 20 \mathrm{~mm}$ glucose $(300-310$ mOsm), with $\left.95 \% \mathrm{O}_{2} / 5 \% \mathrm{CO}_{2}\right]$ at room temperature, the slices were transferred into the recording chamber and superfused $(2-3 \mathrm{ml} / \mathrm{min})$ with warm $\left(30-32^{\circ} \mathrm{C}\right) \mathrm{ACSF}$.

Whole-cell electrophysiology. Whole-cell recordings were obtained from cell bodies of layer III/IV thalamorecipient neurons. Cell bodies of these neurons were found within the first $30-50 \%$ of the slice from the pial surface and were visualized using laser-scanning Dodt contrast imaging (Dodt et al., 2002). Patch pipettes (open pipette resistance, 4-5 $\mathrm{M} \Omega$ ) were filled with an internal solution containing $125 \mathrm{~mm} \mathrm{CsMeSO}$, 2 mм CsCl, 10 mм HEPES, 0.1 mм EGTA, 4 mм MgATP, 0.3 mм NaGTP, $10 \mathrm{~mm} \mathrm{Na}_{2}$ creatine phosphate, $5 \mathrm{~mm}$ QX-314, $5 \mathrm{~mm}$ tetraethylammonium $\mathrm{Cl}$, and 10-25 $\mu \mathrm{M}$ Alexa 594 (pH 7.4 was adjusted with $\mathrm{CsOH}$, 290-295 mOsm). QX-314 was included to block the generation of action potentials in recorded neurons. Alexa 594 was added for visualization of dendritic structures during all experiments. Only neurons with dendritic spines (indicative of excitatory neurons) and a well established primary apical dendrite extending to the pial surface (indicative of pyramidal neurons) were chosen. In the ACX of many mammalian species, pyramidal (not stellate) neurons are the principal cells in the thalamorecipient layers (Lund, 1973; Feldman and Peters, 1978; Smith and Populin, 2001; Richardson et al., 2009). In some experiments, the low-affinity calcium indicator Fluo-5F $(300 \mu \mathrm{M})$ was added to the internal solution. Neurons with any sign of dendritic damage were excluded from analysis.

Voltage-clamp recordings were made using a Multiclamp 700B (Molecular Devices), digitized (10 kHz; DigiData 1322A; Molecular Devices), and recorded using pCLAMP 10.0 software (Molecular Devices). EPSCs were recorded at holding membrane potentials of $-70 \mathrm{mV}$. In some experiments, IPSCs were recorded concomitantly with EPSCs. IPSCs were recorded by switching holding membrane potentials to voltages that corresponded to EPSC reversal potentials $(-10$ to $0 \mathrm{mV})$. In all experiments, membrane potentials were corrected for a liquid junction potential of $-10 \mathrm{mV}$. EPSCs and IPSCs were evoked by current pulses (100 $\mu$ s duration) delivered to thalamic afferents via tungsten bipolar electrodes (FHC) placed in the superior thalamic radiation, midway between the MGv and the $\mathrm{ACx}$ (rostral to the hippocampus). To ensure the specificity of LTD in thalamic inputs, independent intracortical inputs were concurrently tested with thalamic inputs by placing a second stim- ulating electrode in cortical layer $\mathrm{I}, \sim 200 \mu \mathrm{m}$ lateral to the recording pipette. Stimulation intensities $(50-300 \mu \mathrm{A})$ were adjusted during each experiment to elicit 150-200 pA EPSCs. In some experiments, inhibitory inputs were blocked using $\mathrm{GABA}_{\mathrm{A}}$ blocker picrotoxin. Because bath application of picrotoxin causes epilepsy-like activity in TC slices and prevents the reliable recording of TC EPSCs and IPSCs, picrotoxin ( $2-5 \mathrm{~mm})$ was added to the intracellular solution as previously described (Inomata et al., 1988; Metherate and Ashe, 1993; Nelson et al., 1994; YazakiSugiyama et al., 2009). This effectively blocked IPSCs in recording neurons without inducing epilepsy-like activity in the slice.

It is generally challenging to ensure specific stimulation of thalamic afferents in TC slices using extracellular stimulation (Beierlein and Connors, 2002) because cortex and thalamus are reciprocally connected and their axons are adjacent. Furthermore, because thalamorecipient neurons in the cortex are interconnected, stimulation of TC afferents may polysynaptically activate intracortical feedforward excitatory synapses. Therefore, EPSCs recorded in layer III/IV cortical neurons may contain monosynaptic (TC) and polysynaptic (corticothalamic and/or corticocortical) components. We dissected a monosynaptic component using quantification of the initial slopes of EPSCs throughout the LTD experiments (see Fig. 1) (see below). Typically, EPSC slopes were chosen within the first $2 \mathrm{~ms}$ of the EPSC trace based on the uniformity of the slope. This measurement window was chosen based on the observation that IPSC initiation, which is activated bisynaptically, was delayed by $\sim 2$ ms after EPSCs (see Fig. 1b). Indeed, initial slopes of EPSCs evoked by white matter stimulation had short onset latencies ( $\leq 5 \mathrm{~ms}$ ) (mean onset latency, $2.7 \pm 0.09 \mathrm{~ms} ; 15$ neurons) and low onset latency variability jitter $(0.42 \pm 0.17 \mathrm{~ms} ; 15$ neurons), suggestive of activation of monosynaptic TC connections but not of detectable activation of polysynaptic connections during this $2 \mathrm{~ms}$ window.

To ensure consistent access resistance of the recording electrode during the entire experiment, we monitored the peak amplitude of a brief ( 10 $\mathrm{ms}$ ) hyperpolarizing test pulse $(-5 \mathrm{mV})$ given $250 \mathrm{~ms}$ after thalamic stimulation or glutamate uncaging. Access resistance in recorded neurons was typically $10-25 \mathrm{~m} \Omega(17.30 \pm 0.83 \mathrm{~m} \Omega ; n=20)$. Recordings were discarded if access resistance was $>25 \mathrm{~m} \Omega$ or if access resistance changed $>20 \%$ during the course of the whole-cell recording.

Two-photon imaging and glutamate uncaging. Two-photon laserscanning microscopy was performed using an Ultima imaging system (Prairie Technologies), a Ti:sapphire Chameleon Ultra femtosecondpulsed laser (Coherent), and $60 \times(0.9 \mathrm{NA})$ water-immersion infrared objectives (Olympus). To visualize dendrites and dendritic spines, we included Alexa 594 (820 nm excitation wavelength) in the intracellular solution. Dendritic spines were identified as protrusions emanating from a dendritic shaft. Based on previous data (Richardson et al., 2009), dendritic spines that were within $100 \mu \mathrm{m}$ of the soma on basal or oblique dendrites were chosen as putative sites of thalamic inputs.

To identify active thalamic inputs, the fluorescent calcium indicator Fluo $5 \mathrm{~F}(300 \mu \mathrm{M})$ was added to the intracellular solution. Line scans (500 $\mathrm{Hz}$ ) were performed through visible dendritic spines on dendrites of a recorded neuron, and calcium transients (i.e., changes in Fluo 5F fluorescence) were sought in current-clamp mode. Time-locked calcium transients in a dendritic spine in response to a single thalamic stimulation served as an indicator of an active thalamic input. Typically, several dozen spines were scanned during each experiment to identify a spine that responded to thalamic stimulation with a calcium transient. The following criteria were used to confirm that an identified dendritic spine was monosynaptically connected to a stimulated thalamic afferent: brief latency between stimulus and the onset of calcium transient $(<5 \mathrm{~ms})$, low variability in onset latencies $(<1.5 \mathrm{~ms}$ ), and peak calcium transients in a spine that were stronger than those in parent dendrites (Richardson et al., 2009).

For TGU, 4-methoxy-7-nitroindolinyl-caged-L-glutamate (MNIglutamate) $(2.5 \mathrm{~mm}$ ) was added to the recording ACSF. The timing and intensity of glutamate uncaging were controlled by TriggerSync (Prairie Technologies). In typical experiments, we delivered $0.2-0.5 \mathrm{~ms}$ pulses from a second Ti:sapphire Chameleon Ultra laser $(720 \mathrm{~nm})$ to a targeted dendritic spine and recorded uncaging-induced EPSCs (uEPSCs). We delivered 6-10 test pulses around the perimeter of the spine head to 
determine the optimal site of uncaging (determined as the maximal uEPSC). The duration and intensity of illumination of the uncaging laser was then adjusted to induce responses that mimic miniature spontaneous EPSCs, which were previously recorded in layer III/IV neurons and averaged $\sim 10-15 \mathrm{pA}$ (Richardson et al., 2009). We then used these uncaging parameters (site, laser duration, and laser intensity) to conduct the TGU-induced LTD (TGU-LTD) experiments.

FM 1-43 assay in thalamocortical slices. Two-photon imaging of FM 1-43 destaining of presynaptic boutons was performed as a modification of the method described previously (Zakharenko et al., 2002, 2003). A field of view in the ACx of an acute auditory TC slice was selected by performing whole-cell recording from a layer III/IV neuron to ensure that this neuron received monosynaptic thalamic inputs (see above). Thalamic stimulation intensity was adjusted to evoke $150-200 \mathrm{pA}$ EPSCs. After the field of view was selected, the whole-cell pipette was withdrawn, and FM 1-43 (5 $\mu \mathrm{M})$ was washed in for 20-30 min. Dye loading of presynaptic boutons was performed by using $10 \mathrm{~Hz}$ thalamic stimulation for $2 \mathrm{~min}$ in the presence of $\mathrm{NBQX}(1.5 \mu \mathrm{M})$ to avoid activation of postsynaptic neurons and to prevent polysynaptic activity. ADVASEP-7 (200 $\mu \mathrm{M}$; Biotium) was then washed in for 20-30 min to remove the extracellular FM 1-43 dye. Loaded presynaptic boutons were visualized using two-photon imaging $(900 \mathrm{~nm})$. A series of 10 images at different focal planes was acquired every $30 \mathrm{~s}$. Each image was $512 \times 512$ pixels $(33.6 \times 33.6 \mu \mathrm{m}), 0.066 \mu \mathrm{m} /$ pixel in the $x-y$-axes, and images were separated by $1 \mu \mathrm{m}$ steps in the $z$ direction.

Images in each $z$-section series were aligned and analyzed using custom software written in Interactive Data Language (IDL) (ITT Visual Information Solutions). Images showing projections of maximal $z$-axis intensity were made for each subset of a given stack. Puncta were initially identified by a semiautomated procedure written in IDL based on two criteria: (1) fluorescence intensity $>2 \times$ SDs above the mean background and (2) diameter between 0.3 and $2 \mu \mathrm{m}$.

Fluorescence measurements were made by spatially averaging signals over a region, centered over each of the identified puncta, for each time point, during the unloading protocol. Images at successive time points were checked for overlap to help track puncta, which underwent small random movements. Puncta that underwent considerable lateral movement or $>20 \%$ loss of their fluorescent intensity without synaptic stimulation due to photobleaching were excluded from the analysis. The spatially averaged, activity-dependent fluorescence intensity of each punctum obtained at each time point during the unloading procedure was then normalized by the initial fluorescence intensity of that punctum following the FM 1-43-loading procedure before unloading. The unloading procedure consisted of $1 \mathrm{~Hz}$ synaptic stimulations for $15 \mathrm{~min}$ (same as the LTD induction protocol). This unloading procedure was followed by $10 \mathrm{~Hz}$ stimulation applied for 2 min to maximally release FM 1-43 from boutons. Decay of intensity during the $1 \mathrm{~Hz}$ unloading procedure was fitted to a single exponential function by using a custom-made routine written in IDL, and FM 1-43 destaining half-times $\left(t_{1 / 2}\right)$ for every punctum were calculated. The rate of destaining for each punctum was expressed as $1 / t_{1 / 2}$. Puncta for which fluorescence intensities during unloading could not be fitted to a single exponential function were not included in the analysis.

Long-term depression experiments. LTD was induced by either synaptic stimulation or TGU. Synaptically induced LTD was induced by a lowfrequency train $(900$ pulses at $1 \mathrm{~Hz})$ of square electrical pulses $(100 \mu \mathrm{s})$ delivered to thalamic afferents. TGU-LTD was induced by an identical train of glutamate photolysis to a single dendritic spine. In all LTD experiments, baseline EPSCs were recorded using test stimulations in voltage-clamp mode (holding potential, $-70 \mathrm{mV}$ ) for $5-10 \mathrm{~min}$ before induction of LTD. For synaptic experiments, we delivered a pair of test stimulations $(0.05 \mathrm{~Hz})$ with interstimulus interval of $50 \mathrm{~ms}$. Paired-pulse depression of monosynaptic EPSCs ensured that we stimulated thalamic afferents. For TGU experiments, we delivered a train of single TGU pulses at $0.016 \mathrm{~Hz}$. Both types of LTDs were induced in current-clamp mode while maintaining a steady resting potential of $-70 \mathrm{mV}$ using slow $(\tau=5 \mathrm{~s})$ current injection. After induction, the recordings were resumed in voltage-clamp mode at the same preinduction stimulation rate. In some experiments, we measured synaptically induced LTD of EPSCs and
IPSCs by alternating membrane holding potentials between $-70 \mathrm{mV}$ and EPSC reverse potentials ( -10 to $0 \mathrm{mV}$ ) as previously described (Froemke et al., 2007). In addition, in most experiments, we monitored changes in EPSCs and IPSCs evoked by independent intracortical stimuli by alternating test pulses between thalamic and layer I stimulations at $0.05 \mathrm{~Hz}$. In these experiments, the $1 \mathrm{~Hz}$ induction protocol was applied to thalamic but not to intracortical inputs. Pharmacological agonists or inhibitors were applied 15-30 min before induction of LTD and were washed out at the end of LTD induction.

LTD experiments were analyzed off-line. For synaptically induced LTD, we compared EPSCs (initial $2 \mathrm{~ms}$ slope) recorded 40-60 min after LTD induction with baseline EPSCs recorded before LTD induction. For TGU-LTD, we compared uEPSCs recorded 35-60 min after LTD induction with baseline uEPSCs. During TGU-LTD induction, precautions were taken to ensure that the TGU induction protocol delivered 900 pulses to a dendritic spine without damaging it or its parent dendrite. We monitored the dendritic spine position to ensure that the site of photolysis did not drift $>0.5 \mu \mathrm{m}$ during induction. The success of glutamate uncaging during LTD induction was also monitored by detecting uEPSPs. Experiments were discarded if TGU during LTD induction failed to produce detectable uEPSPs or if a targeted dendritic spine or its surrounding neuropil showed signs of distress due to local overheating. Durations and intensities of synaptic stimulation and TGU pulses remained constant throughout an experiment.

Statistical analyses. Data are represented as means \pm SEM. All statistics were computed using SigmaPlot and SigmaStat software (Systat Software). In FM 1-43 experiments, the differences in the mean values among treatment groups were analyzed using one-way ANOVA. Experimental groups were compared pairwise by using the Bonferroni $t$ test. LTD expression was determined by paired $t$ test if the normality (ShapiroWilk) test passed or by Wilcoxon's signed rank test if the normality test failed. LTD was considered significant if the $p$ value of the test result was $<0.05$.

\section{Results}

\section{Postsynaptic LTD persists at mature TC synapses}

In this study, we used mice that had matured beyond the critical period for synaptic plasticity at TC synapses (P35-P42). In slices containing the auditory thalamus and $\mathrm{ACX}$, we performed wholecell recordings from thalamorecipient layer III/IV excitatory neurons in the $\mathrm{ACx}$ (Fig. 1a) and recorded EPSCs evoked by thalamic stimulation. Using two-photon imaging, we ensured that all recorded neurons were pyramidal neurons that have dendritic spines and an extended apical dendrite reaching the pial surface. As was shown previously, these pyramidal neurons are the predominant thalamorecipient cells in the ACx (Lund, 1973; Feldman and Peters, 1978; Smith and Populin, 2001; Richardson et al., 2009). These neurons had an average resting membrane potential of $-69.7 \pm 1.0 \mathrm{mV}$ and an input resistance of $282.3 \pm 19.6$ $\mathrm{M} \Omega(n=20)$. White matter stimulation evoked EPSCs in layer III/IV neurons with onset latency $2.70 \pm 0.09 \mathrm{~ms}(n=15)$ and low onset latency variability $(0.42 \pm 0.17 \mathrm{~ms} ; n=15)$. These EPSCs initiated $2.0 \pm 0.16 \mathrm{~ms}$ ( $p<0.01 ; 15$ neurons) earlier than the onset of bisynaptic IPSCs recorded in the same neurons (Froemke et al., 2007) (Fig. 1b), suggesting a monosynaptic nature of the initial slope of EPSCs evoked by activation of thalamic afferents. Consistent with previous reports (Stratford et al., 1996; Gil et al., 1999; Rose and Metherate, 2005; MacLean et al., 2006; Lee and Sherman, 2008), pairs of thalamic stimuli produced pairedpulse depression of EPSCs (Fig. 1b), whereas paired stimulation of the independent intracortical input produced paired-pulse facilitation (data not shown). After establishing that we were recording monosynaptic TC EPSCs, we next tested whether TC synapses underwent LTD. Consistent with the idea of a critical period for LTD at TC synapses (Daw et al., 2007), a conventional induction protocol (900 electrical stimuli at $1 \mathrm{~Hz}$ ) applied to 


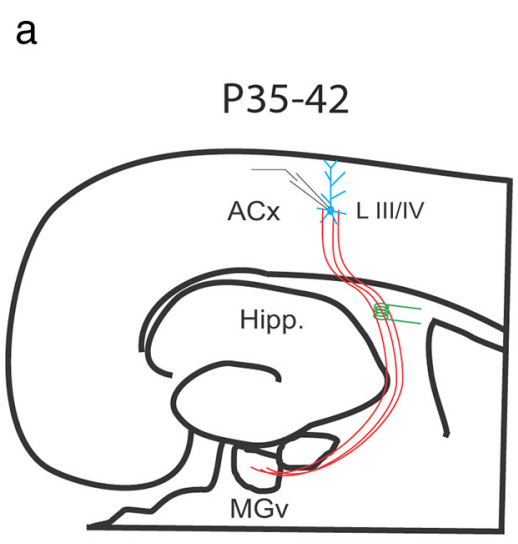

b 二 Thalamic EPSCS
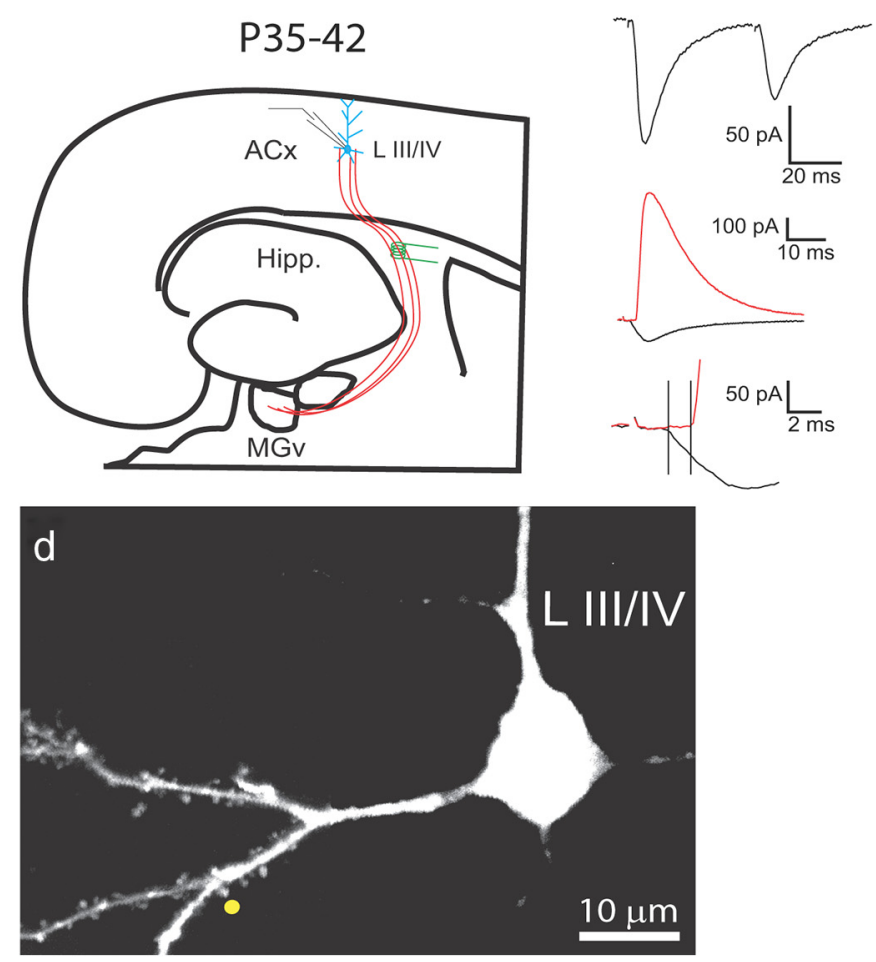

Alexa 594 Fluo 5F
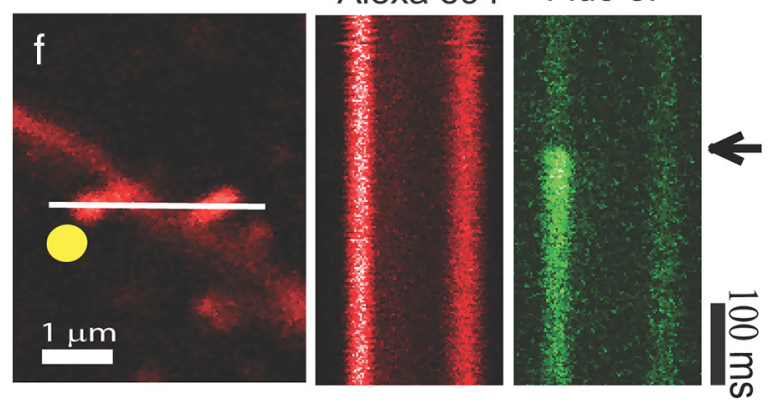
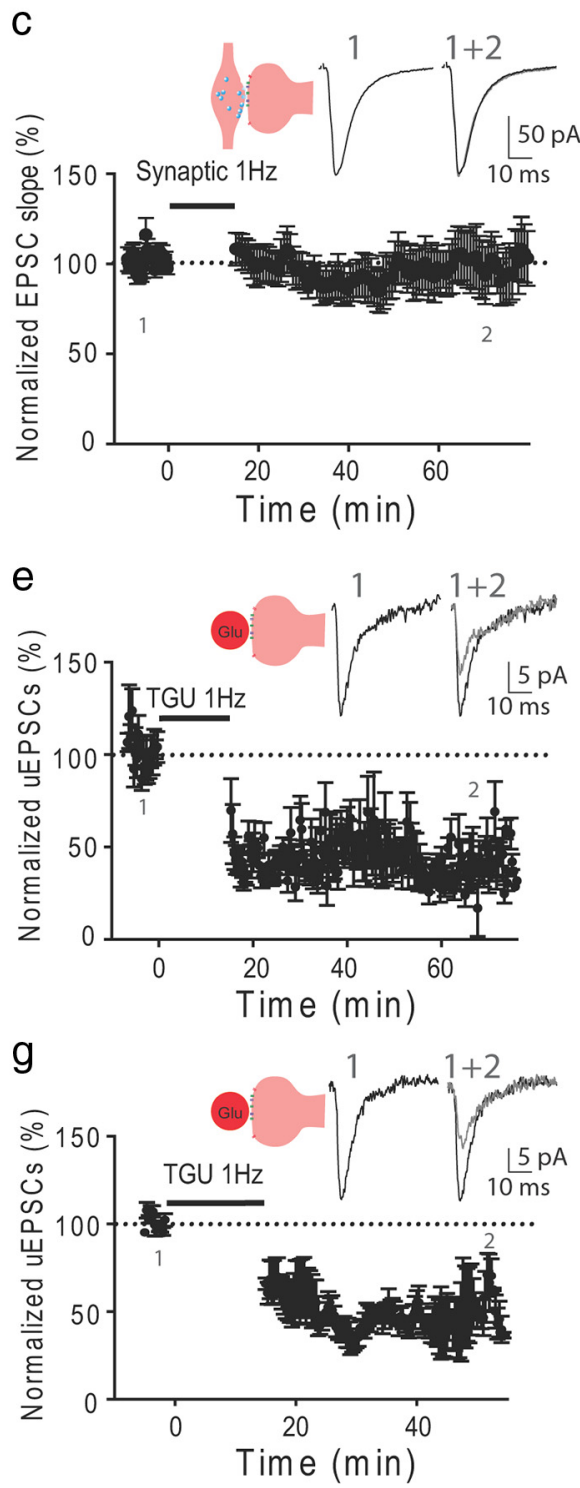

Figure 1. Two-photon glutamate uncaging unmasks LTD at mature TC synapses in the ACx. a, Diagram of a TC slice from a mature (P35-P42) mouse containing the ventral portion of the medial geniculate nuclei (MGv), hippocampus (Hipp), and ACx. $\boldsymbol{b}$, The top panel shows a representative trace of two EPSCs evoked by paired stimulation of thalamic afferents (50 ms interpulse interval). The middle panel depicts representative traces of EPSC and IPSC recorded at -70 and $0 \mathrm{mV}$ holding potentials $\left(V_{\mathrm{h}}\right)$, respectively, and evoked by stimulation of thalamic afferents. The bottom panel of the same traces shows that the EPSC is evoked $\sim 2$ ms earlier than the IPSC recorded in the same neuron. The vertical bars show the time interval in which the monosynaptic component of the EPSC slope was measured. $\boldsymbol{c}$, Stimulation ( 900 stimuli at $1 \mathrm{~Hz}$ ) of thalamic afferents failed to induce LTD in thalamorecipient layer III/IV neurons. $\boldsymbol{d}, \boldsymbol{e}$, TGU ( 900 pulses at $1 \mathrm{~Hz}$ ) induced LTD at putative thalamic inputs ( $\boldsymbol{d}$, yellow dot). $\boldsymbol{f}, \boldsymbol{g}$, Active thalamic inputs were identified ( $\boldsymbol{f}$, yellow dot), and TGU-LTD was induced at those inputs ( $\boldsymbol{g}$ ). The insets show representative EPSCs or uEPSCs (averaged from 5 traces) recorded before (1) and after (2) induction of LTD.

thalamic afferents failed to produce LTD at mature TC synapses in the $\mathrm{ACx}$ (Fig. 1c). The initial slope of EPSCs (Fig. 1b) measured after this LTD induction protocol was $96.8 \pm 13.8 \%$ of the preinduction baseline EPSC slope $[p=0.75 ; 0$ of 11 neurons ( 0 of 11 ) showed a significant $(p<0.05)$ decrease of the EPSC slope].

We hypothesized that if LTD acquires a gating mechanism, such a mechanism could be localized within the intricate TC circuitry that is presynaptic to thalamic inputs on layer III/IV neurons, and by bypassing this circuitry, we might unmask TC LTD. To this end, we used TGU to activate individual dendritic spines, the postsynaptic sites of thalamic inputs. Because TGU releases exogenous glutamate and thereby bypasses the release of endogenous neurotransmitter from presynaptic terminals, this method tests for only postsynaptic mechanisms of synaptic function (Matsuzaki et al., 2001). Previously, we determined that tha- lamic inputs preferentially synapse onto dendritic spines within $100 \mu \mathrm{m}$ of the soma (Richardson et al., 2009). We targeted these proximal spines with TGU (Fig. 1d) and evoked uEPSCs that mimicked miniature EPSCs (Richardson et al., 2009). After establishing a stable baseline of uEPSCs at an individual dendritic spine, we applied the TGU-LTD induction protocol (900 TGU pulses at $1 \mathrm{~Hz}$ ), which produced a robust LTD (TGU-LTD) (Fig. $1 e$ ). The mean uEPSC measured after induction was $47.8 \pm 8.4 \%$ of baseline uEPSCs ( $p=0.001 ; 5$ of 6 neurons).

To ensure that LTD was induced in actual (rather than putative) thalamic inputs, we performed similar experiments at functional thalamic inputs identified by using the fluorescent calcium indicator Fluo 5F. We added Fluo 5F to the intracellular solution and first searched for dendritic spines that responded to a single electrical stimulation of thalamic afferents with a monosynaptic 
calcium transient (Fig. 1f). We regarded these dendritic spines as active thalamic inputs (Richardson et al., 2009). After an active thalamic input was identified, we targeted this spine with TGU, established a stable baseline of uEPSCs at $0.016 \mathrm{~Hz}$, and then applied the TGU-LTD induction protocol. Active thalamic inputs, similar to putative thalamic inputs, underwent a robust TGU-LTD $(56.3 \pm 11.5 \%$ of baseline; $p=0.024 ; 4$ of 5 neurons) (Fig. $1 g$ ). Together, these experiments showed that long-term synaptic plasticity in the form of LTD is not eliminated at mature TC inputs. These experiments also showed that LTD at mature TC synapses can be expressed postsynaptically. The failure of synaptic stimulation to express LTD at these synapses also suggests that postsynaptically expressed LTD is gated by presynaptic mechanisms.

TGU-LTD depends on group I mGluRs TGU-LTD showed features of postsynaptically expressed LTD previously described at other synapses (Malenka and Bear, 2004; Collingridge et al., 2010). The calcium chelator BAPTA (10 mM) added to intracellular solution eliminated TGULTD $(101.2 \pm 12.9 \%$ of baseline; $p=$ 0.916; 0 of 6 neurons) (Fig. 2a), as did the nonselective mGluR antagonist $\alpha$-methyl4-carboxyphenylglycine (MCPG) (300 $\mu \mathrm{M})(93.8 \pm 4.7 \% ; p=0.218 ; 0$ of 9 neurons) (Fig. $2 b)$ and group I mGluR antagonists 2-methyl-6-(phenylethynyl) pyridine hydrochloride (MPEP) (10 $\mu \mathrm{M} ; \mathrm{mGluR}_{5}$ antagonist $)$ and (-)-ethyl-(7E)-7-hydroxyimino-1,7a-dihydrocyclopropa $[b]$ chromene-1a-carboxylate (CPCCOEt) (40 $\mu \mathrm{M} ; \mathrm{mGluR}_{1}$ antagonist) $(101.8 \pm 9.6 \% ; p=0.887 ; 0$ of 5 neurons) (Fig. $2 c)$. The NMDA receptor (NMDAR) antagonist D-APV $(50 \mu \mathrm{M})(56.5 \pm 8.7 \%$; $p=$ 0.001; 7 of 7 neurons) did not block TGU-LTD (Fig. 2d). Thus, TGU-LTD depends on group I mGluRs and intracellular $\mathrm{Ca}^{2+}$ but not NMDARs.

\section{Pairing-LTD and TGU-LTD engage the same postsynaptic mechanisms}

Because stimulation of thalamic afferents alone cannot evoke postsynaptic LTD at mature TC synapses, additional mechanisms may be necessary to unmask it. Acetylcholine (ACh) originating from the nucleus basalis and acting through muscarinic receptors is required for RF plasticity in the $\mathrm{ACx}$ of mature animals (Kilgard and Merzenich, 1998a,b; Weinberger, 2004; Froemke et al., 2007). We therefore hypothesized that if TC plasticity is a cellular substrate of RF plasticity, then a similar mechanism should gate LTD at TC synapses. Accordingly, we paired $1 \mathrm{~Hz}$ electrical stimulation of thalamic afferents with bath application of the cholinergic receptor agonist carbachol (CCh) $(5 \mu \mathrm{M})$, and this protocol induced robust LTD (pairing-LTD) $(58.2 \pm 8.2 \%$ of baseline; $p=0.007 ; 5$ of 6 neurons) (Fig. 3a). Pairing-LTD was specific to the thalamic input; the control intracortical input that was exposed to $\mathrm{CCh}$ but did not receive $1 \mathrm{~Hz}$ stimulation was not depressed ( $105.1 \pm 8.8 \%$ of baseline; $p=0.72 ; 0$ of 6 neurons) (Fig. 3a).
Thalamic stimulation and cholinergic activation were both necessary for pairing-LTD. Thus, $1 \mathrm{~Hz}$ thalamic stimulation alone was not sufficient to produce LTD at TC mature synapses (Fig. 1c). Similarly, CCh alone was not sufficient to produce LTD of either EPSCs or IPSCs at TC mature synapses $(102.7 \pm 2.5 \%$ of baseline for EPSCs, $p=0.385$; and $104.9 \pm 11.2 \%$ of baseline for IPSCs, $p=0.70 ; 0$ of 5 neurons) (Fig. $3 b$ ). Despite robust LTD of TC EPSCs induced by the pairing protocol, the paired-pulse ratio (PPR) of two consecutive TC EPSCs did not change following induction, suggesting that pairing-LTD is similar to TGU-LTD in that it is expressed postsynaptically at mature TC synapses. Thus, PPR of EPSCs (50 ms interpulse interval) was $0.74 \pm 0.12$ and $0.71 \pm 0.14$ before and $60 \mathrm{~min}$ after induction of pairing-LTD, respectively ( $p=0.85 ; 5$ neurons).

Pairing-LTD was also mechanistically similar to TGU-LTD in that intracellular BAPTA prevented pairing-LTD (113.6 $\pm 10.2 \%$ of baseline; $p=0.232 ; 0$ of 5 neurons) (Fig. $3 c$ ), and pairing-LTD did not depend on NMDARs but did depend on group I mGluRs (Fig. $3 d$ ). The pairing protocol reduced EPSCs to $35.9 \pm 12.1 \%$ ( $p=0.019 ; 4$ of 4 neurons) of the baseline in the presence of D-APV but only to $87.7 \pm 14.8 \%$ ( $p=0.524 ; 1$ of 5 neurons) in the presence of MCPG and $96.7 \pm 10.9 \%(p=0.784 ; 0$ of 5 neurons) in the presence of MPEP and CPCCOEt. These findings indicate that pairing-LTD and TGU-LTD engage the same postsynaptic mechanisms at mature TC synapses.

Synaptic plasticity at inhibitory synapses does not contribute to pairing-LTD

Pairing-LTD was not caused by plasticity at inhibitory synapses. Coincident recordings of IPSCs showed that the pairing protocol 

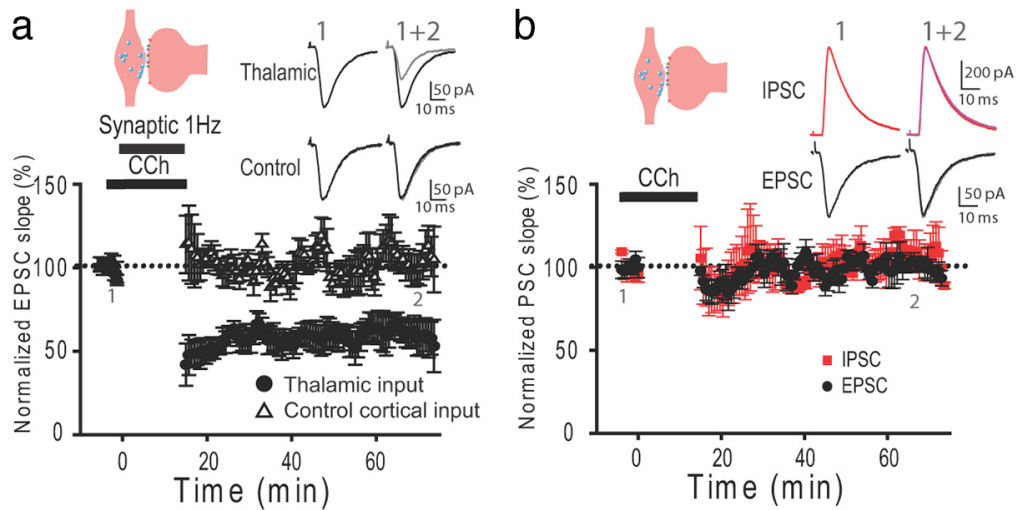

C

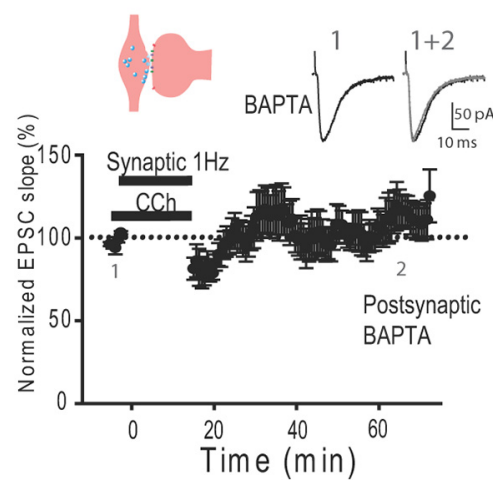

Figure 3. Pairing of thalamic stimulation with activation of cholinergic receptors is sufficient to induce LTD at mature TC synapses. $\boldsymbol{a}$, Pairing of thalamic stimulation ( 900 stimuli at $1 \mathrm{~Hz}$ ) with bath application of CCh $(5 \mu \mathrm{m})$ produced LTD of EPSCS at mature TC synapses (pairing-LTD). Control intracortical inputs that did not receive $1 \mathrm{~Hz}$ stimulation were not depressed. $\boldsymbol{b}$, CCh application alone failed to depress EPSCs and IPSCs. c, Postsynaptic intracellular BAPTA abolished pairing-LTD. d, Pairing-LTD was blocked by MCPG or MPEP and CPCCOEt but not by D-APV. The insets show representative EPSCs or IPSCs (averaged from 5 traces) recorded before (1) and after (2) induction of LTD.

induced only a short-term depression of IPSCs that later recovered to $124.5 \pm 24.5 \%$ of baseline ( $p=0.36$; 0 of 6 neurons exhibited LTD of IPSCs) (Fig. 4a). To directly test the role of inhibitory neurotransmission in pairing-LTD, we blocked IPSCs using the $\mathrm{GABA}_{\mathrm{A}}$ ion channel blocker picrotoxin. Because extracellular application of picrotoxin typically induces epileptic activity in slices (data not shown), we included picrotoxin (2-5 $\mathrm{mm}$ ) in the intracellular solution. Intracellular picrotoxin effectively blocked IPSCs evoked by thalamic stimulation (Fig. $4 b$ ) without inducing epileptic activity in slices. We found that pairing-LTD of EPSCs was not inhibited by the presence of intracellular picrotoxin $(58.6 \pm 9.1 \%$ of the baseline; $p=0.01 ; 4$ of 5 neurons) (Fig. 4c), indicating that pairing-LTD does not depend on changes in inhibitory synapses.

\section{$M_{1}$ muscarinic receptors are required for pairing-LTD}

Because postsynaptic TGU-LTD does not require cholinergic activation and pairing-LTD does, we hypothesized that cholinergic receptors that unmask TC LTD are involved presynaptically. To identify the nature of these receptors, we replaced CCh in the pairing protocol with agonists of muscarinic or nicotinic receptors. We found that muscarinic but not nicotinic receptors were necessary for pairing-LTD (Fig. 5). When we replaced CCh with muscarinic agonists muscarine or pilocarpine, the mean EPSC decreased to $56.9 \pm 7.2 \%$ ( $p=0.002 ; 6$ of 6 neurons) of baseline with muscarine and to $52.8 \pm 11.8 \%$ ( $p=0.034 ; 4$ of 4 neurons) with pilocarpine (Fig. $5 a$ ). In contrast, the mean EPSC did not deviate from baseline during the pairing protocol with nicotinic

agonists nicotine $(116.3 \pm 14.9 \% ; p=$ 0.189 ; 0 of 5 neurons) or epibatidine (104.5 $\pm 10.4 \% ; p=0.73 ; 0$ of 5 neurons) (Fig. 5b). Further experiments revealed that $\mathrm{M}_{1}$ (but not $\mathrm{M}_{2}$ or $\mathrm{M}_{4}$ ) muscarinic receptors are required for pairing-LTD. LTD induced by pairing of CCh and $1 \mathrm{~Hz}$ thalamic stimulation was inhibited in the presence of the $\mathrm{M}_{1} \mathrm{R}$ inhibitor telenzepine $(92.3 \pm 12.2 \%$ of baseline; $p=0.687 ; 1$ of 5 neurons) but not in the presence of a mixture containing $\mathrm{M}_{2} \mathrm{R}$ and $\mathrm{M}_{4} \mathrm{R}$ inhibitors 11-[[2-[(diethylamino)methyl]1-piperidinyl] acetyl]-5,11-dihydro-6 $H$-pyrido[2,3-b][1,4]benzodiazepin-6-one (AF-DX116) and 3,6a,11,14-tetrahydro9-methoxy-2-methyl- $(12 H)$-isoquino $[1,2-b]$ pyrrolo[3,2-f][1,3]benzoxazine-1carboxylic acid, ethyl ester (PD102807) (60.4 $\pm 4.3 \%$ of baseline; $p<0.001 ; 6$ of 6 neurons) (Fig. $5 c$ ).

\section{Presynaptic muscarinic receptors control TC LTD}

To test whether muscarinic receptors are involved presynaptically in the gating of pairing-LTD, we compared TGU-LTD and pairing-LTD in the presence of the muscarinic receptor antagonist atropine. For example, it is conceivable that glutamate uncaging could evoke local ACh release and thereby activate nearby postsynaptic cholinergic receptors. However, atropine was ineffective at blocking TGU-LTD $(45.4 \pm 3.9 \%$ of baseline; $p<$ $0.001 ; 6$ of 6 neurons) (Fig. $6 a$ ), which suggests that muscarinic receptors do not operate postsynaptically in TC LTD mechanisms. In contrast, atropine blocked pairing-LTD (99.4 $\pm 9.6 \%$; $p=0.995 ; 0$ of 9 neurons) (Fig. $6 b$ ). Thus, the activation of muscarinic receptors appears to be required for this form of synaptic plasticity, and because they do not operate at the postsynaptic locus, muscarinic receptors most likely control TC LTD presynaptically.

\section{$M_{1}$ muscarinic receptor activity enhances sustained neurotransmitter release at thalamic terminals during LTD induction}

To test directly whether muscarinic receptors affect neurotransmitter release from thalamic presynaptic terminals, we used twophoton imaging of FM 1-43 dye unloading from individual presynaptic boutons (the FM 1-43 assay). We have previously shown that by monitoring the activity-dependent decrease in fluorescence in presynaptic terminals due to exocytosis of FM 1-43loaded synaptic vesicles, this assay can reliably measure the rate of neurotransmitter release from presynaptic terminals in brain slices (Zakharenko et al., 2001, 2003; Earls et al., 2010). We labeled thalamic presynaptic terminals in the ACx by electrically stimulating thalamic afferents at $10 \mathrm{~Hz}$ in the presence of the fluorescent dye FM 1-43. To prevent activation of postsynaptic neurons and to avoid polysynaptic activity, we performed these experiments in the presence of the AMPA receptor blocker NBQX $(1.5 \mu \mathrm{M})$. Thus, the presence of NBQX guaranteed that we measured rates of neurotransmitter release specifically at tha- 

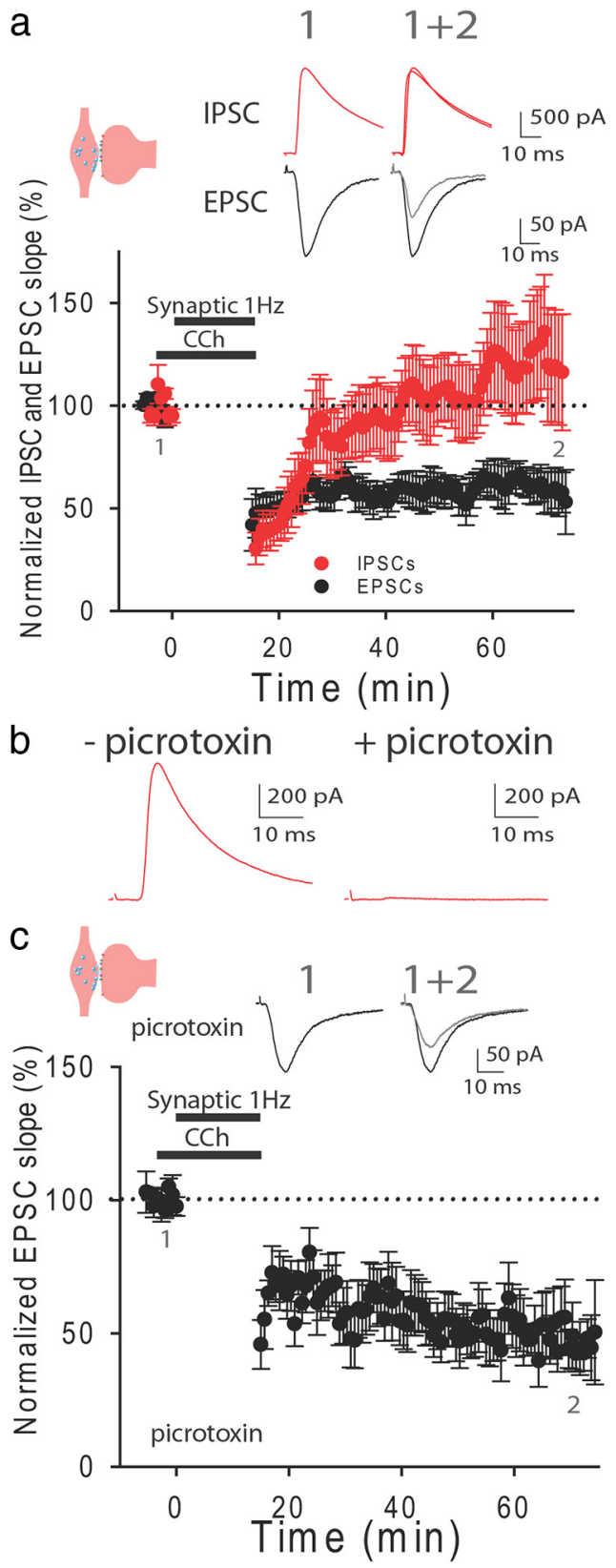

Figure 4. Inhibitory synapses do not contribute to mechanisms of thalamic LTD. $\boldsymbol{a}$, The pairing protocol induces LTD of EPSCs but only short-term depression of IPSCs in thalamorecipient neurons in the ACX. Mean IPSCs and EPSCs as functions of time before and after induction of pairing-LTD. $\boldsymbol{b}$, Representative traces of IPSCs evoked by thalamic stimulation in the presence and absence of intracellular picrotoxin (2 mM). c, Pairing-LTD of EPSCs is preserved in the presence of picrotoxin. The insets show representative EPSCS or IPSCS (averaged from 5 traces) recorded before (1) and after (2) induction of pairing-LTD.

lamic terminals. After loading FM 1-43 and washing out the extracellular dye (see Materials and Methods), we observed fluorescent puncta in the thalamorecipient layers of the ACx. These puncta represented stimulated presynaptic thalamic terminals loaded with FM 1-43 (Fig. 7a). Subsequent stimulation of thalamic afferents that mimics induction of LTD (900 pulses at $1 \mathrm{~Hz})$ unloaded the dye from thalamic terminals (Fig. 7a,b). FM 1-43 destaining from each fluorescent bouton was fitted with a single exponential decay, and destaining rate [measured as the reciprocal value of FM 1-43 destaining half-times $\left.\left(1 / t_{1 / 2}\right)\right]$ was calculated.

We found that the rates of FM 1-43 unloading (and hence the rates of neurotransmitter release) from thalamic presynaptic ter-
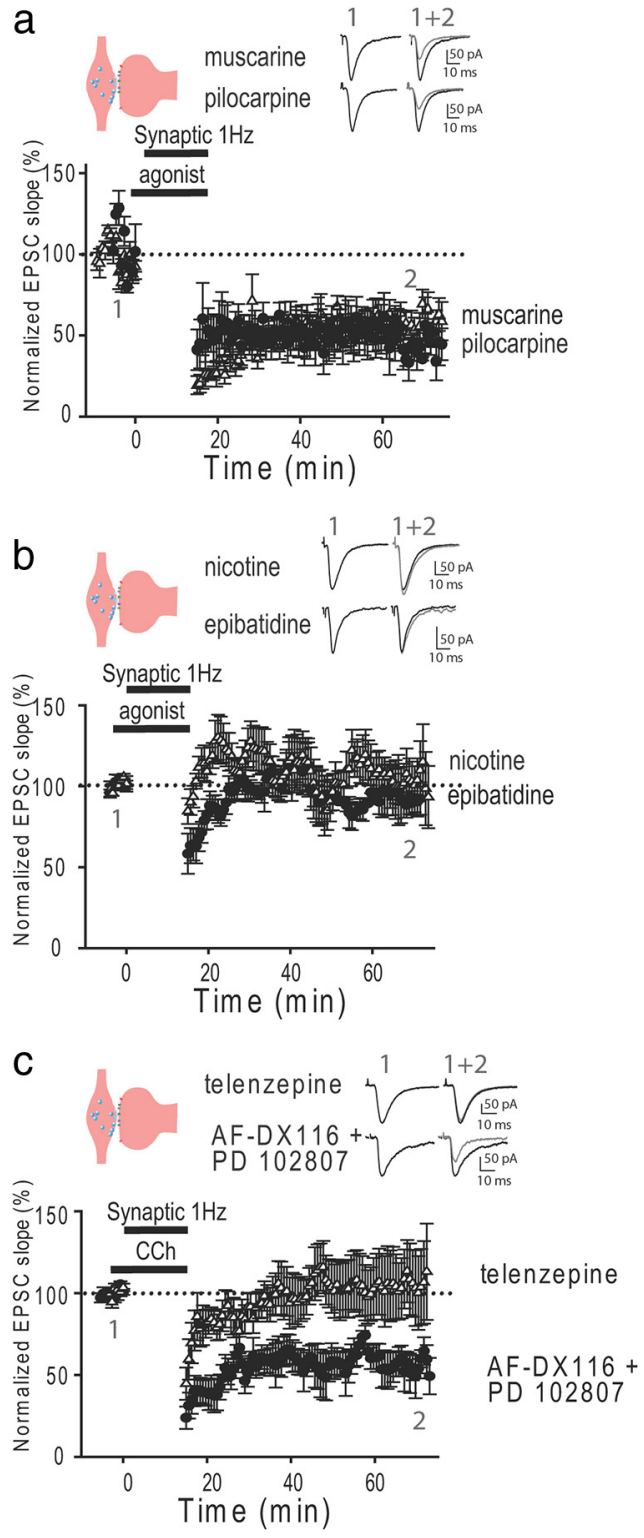

Figure 5. $M_{1}$ muscarinic receptors are required to unmask LTD at mature TC synapses. $\boldsymbol{a}, \boldsymbol{b}$, Pairing thalamic stimulation with muscarinic agonists muscarine $(5 \mu \mathrm{M})$ or pilocarpine $(30 \mu \mathrm{M})$ (a) but not nicotinic agonists nicotine $(5 \mu \mathrm{m})$ or epibatidine $(0.2 \mu \mathrm{M})(\boldsymbol{b})$ was sufficient to induce pairing-LTD. $c, M_{1} R$ inhibitor telenzepine $(0.1 \mu \mathrm{m})$ but not $M_{2} R / M_{4} R$ inhibitors AF-DX116 $(0.1 \mu \mathrm{M})$ and PD102807 $(0.2 \mu \mathrm{m})$ eliminated pairing-LTD. The insets show representative EPSCs (averaged from 5 traces) recorded before (1) and after (2) induction of LTD. Error bars indicate SEM.

minals became significantly faster in the presence of CCh (Fig. $7 b, c)$. On average, the rates of FM 1-43 destaining in the presence of CCh increased to $0.00356 \pm 0.00014 \mathrm{~s} \mathrm{~s}^{-1}$ ( 6 slices, $9-25$ boutons per slice) compared with that in control slices $(0.00244 \pm$ $0.00022 \mathrm{~s}^{-1} ; 6$ slices, $8-28$ boutons per slice; $\left.p=0.002\right)$. These results indicated that the activation of cholinergic receptors is sufficient to increase neurotransmitter release from thalamic afferents during LTD induction. To test whether $\mathrm{M}_{1}$ Rs are responsible for this increase, we measured the rate of FM 1-43 destaining from thalamic afferents in the presence of CCh and the $M_{1} R$ blocker telenzepine. Telenzepine rescued the effect of CCh on thalamic presynaptic function (Fig. $7 b, c$ ). On average, the rate of FM 1-43 destaining in the presence of CCh and telenzepine was $0.00199 \pm 0.00014 \mathrm{~s}^{-1}$ (6 slices, $14-48$ boutons per slice), which 

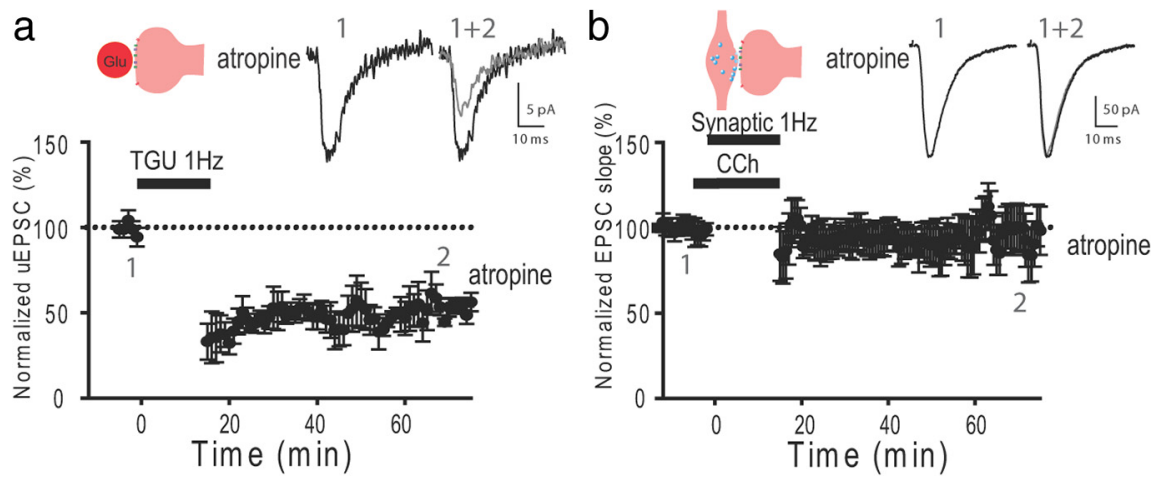

Figure 6. Postsynaptic muscarinic receptors are not required for LTD at mature TC synapses. $\boldsymbol{a}, \boldsymbol{b}$, The muscarinic antagonist atropine $(0.3 \mu \mathrm{m})$ did not block TGU-LTD $(\boldsymbol{a})$ but did block pairing-LTD $(\boldsymbol{b})$. The insets show representative EPSCs or uEPSCs (averaged from 5 traces) recorded before (1) and after (2) induction of LTD.
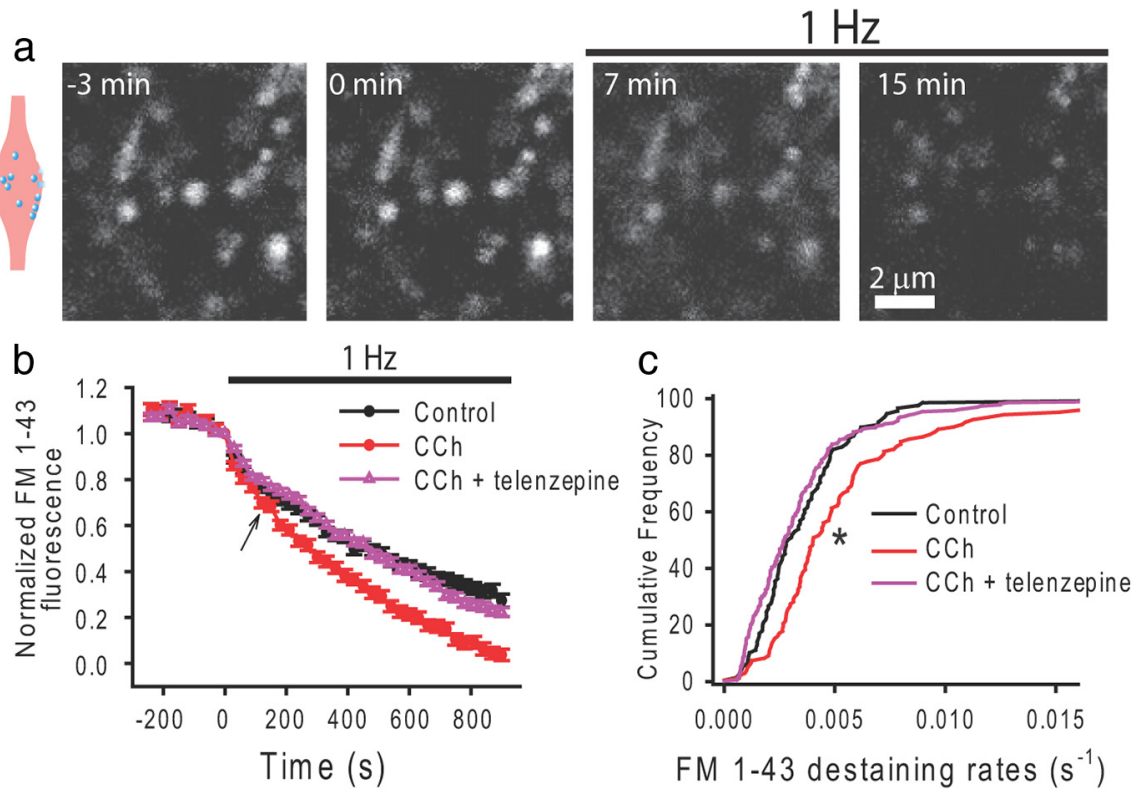

Figure 7. $M_{1}$ muscarinic receptors increase neurotransmitter release from thalamic afferents during LTD induction. $\boldsymbol{a}$, Representative fluorescent images of the same field in the layer III/IV of the $A C x$ at different periods of time during the destaining protocol, in which time 0 is the beginning of $1 \mathrm{~Hz}$ stimulation. $\boldsymbol{b}, \boldsymbol{c}$, Average FM 1-43 destaining curves $(\boldsymbol{b})$ and cumulative histograms of destaining rates (c) for thalamic boutons in control slices and slices treated with CCh or CCh and telenzepine (110-249 boutons). An arrow in $\boldsymbol{b}$ indicates the first time point of significant $(p<0.05)$ difference. ${ }^{*} p<0.001$.

was significantly slower than that in the presence of CCh alone $(p<0.001)$ but comparable with that in control slices $(p=$ $0.123)$. These results indicate that the activation of $\mathrm{M}_{1} \mathrm{Rs}$ is sufficient to increase neurotransmitter release at thalamic afferents during the induction of TC LTD.

Interestingly, the difference in the rates of FM 1-43 destaining between control and CCh-treated slices was not significant until 2 min after the beginning of $1 \mathrm{~Hz}$ stimulation (Fig. $7 b$ ). This result suggests that cholinergic activation increases neurotransmitter release at thalamic afferents only during prolonged synaptic activity. This was confirmed when we measured the PPR of two consecutive thalamic EPSCs in the presence and absence of CCh. Although this assay of presynaptic function is not as direct as the FM 1-43 assay, PPR provides an estimate of short-term plasticity thought to be mediated through presynaptic mechanisms. The PPR of thalamic EPSCs did not significantly differ between control slices and slices treated with CCh (data not shown). This result confirmed that $\mathrm{CCh}$ without prolonged synaptic activity does not affect basal neurotransmitter release at TC synapses. However, FM 1-43 assays showed that prolonged synaptic stimulation (like that used during the induction of LTD) in the presence of CCh increased sustainability of neurotransmitter release at mature TC synapses. These data also suggest that a pattern of synaptic activity that more efficiently activates both glutamatergic and cholinergic inputs will be sufficient to unmask LTD at mature TC synapses.

\section{Paired-pulse pattern of thalamic stimulations unmasks LTD at mature TC synapses}

Previous reports indicated that a lowfrequency train of paired pulses of synaptic stimulation is sufficient to activate both glutamatergic and cholinergic inputs in the hippocampus (Volk et al., 2007; Jo et al., 2010). Deafferented cholinergic fibers from remote nuclei maintain the capability to release ACh when stimulated extracellulary in acute hippocampal slices (Cole and Nicoll, 1983). ACh is released from these fibers more efficiently when the paired-pulse pattern of extracellular stimulation is used. This pattern of synaptic stimulation induces stronger LTD at excitatory synapses of mature animals than does a single-pulse pattern of stimulation (Kemp and Bashir, 1999; Huber et al., 2000; Kemp et al., 2000), and this LTD depends on $\mathrm{M}_{1}$ Rs (Volk et al., 2007; Jo et al., 2010). To test whether a train of paired-pulse stimulations (PPSs) is sufficient to unmask LTD at mature TC synapses, we used a $1 \mathrm{~Hz}$ train of paired pulses (900 pairs; $50 \mathrm{~ms}$ interpulse interval) applied to thalamic afferents. We found that, in contrast to a $1 \mathrm{~Hz}$ train of single pulses (Fig. $1 c$ ), a $1 \mathrm{~Hz}$ train of PPS alone produced a strong LTD (PPS-LTD) at mature TC synapses (Fig. 8a). On average, EPSCs decreased to $39.0 \pm$ $11.5 \%$ after PPS compared with baseline EPSCs ( $p=0.004 ; 5$ of 5 neurons), indicating that PPS alone is sufficient to unmask LTD at mature TC synapses. Similar to TGU-LTD and pairing-LTD, PPS-LTD was blocked in the presence of MPEP and CPCCOEt $(107.9 \pm 8.6 \%$ of the baseline; 0 of 5 neurons; $p=0.422)$. This result indicated that PPS-LTD operates through the same postsynaptic mechanisms as pairing-LTD and TGU-LTD (Fig. 8b). PPS-LTD was also blocked by telenzepine (104.6 $\pm 9.2 \%$ of baseline; 0 of 5 neurons; $p=0.743$ ), confirming that this form of synaptic plasticity is mediated by $M_{1}$ Rs (Fig. $8 c$ ). These results suggest that a train of PPS applied to TC radiations is capable of releasing glutamate from TC projections and also activating cholinergic fibers. Together, these results and other data suggest that ACh release is sufficient to relieve presynaptic gating at TC synapses through activation of $\mathrm{M}_{1} \mathrm{Rs}$, and with activation of postsyn- 

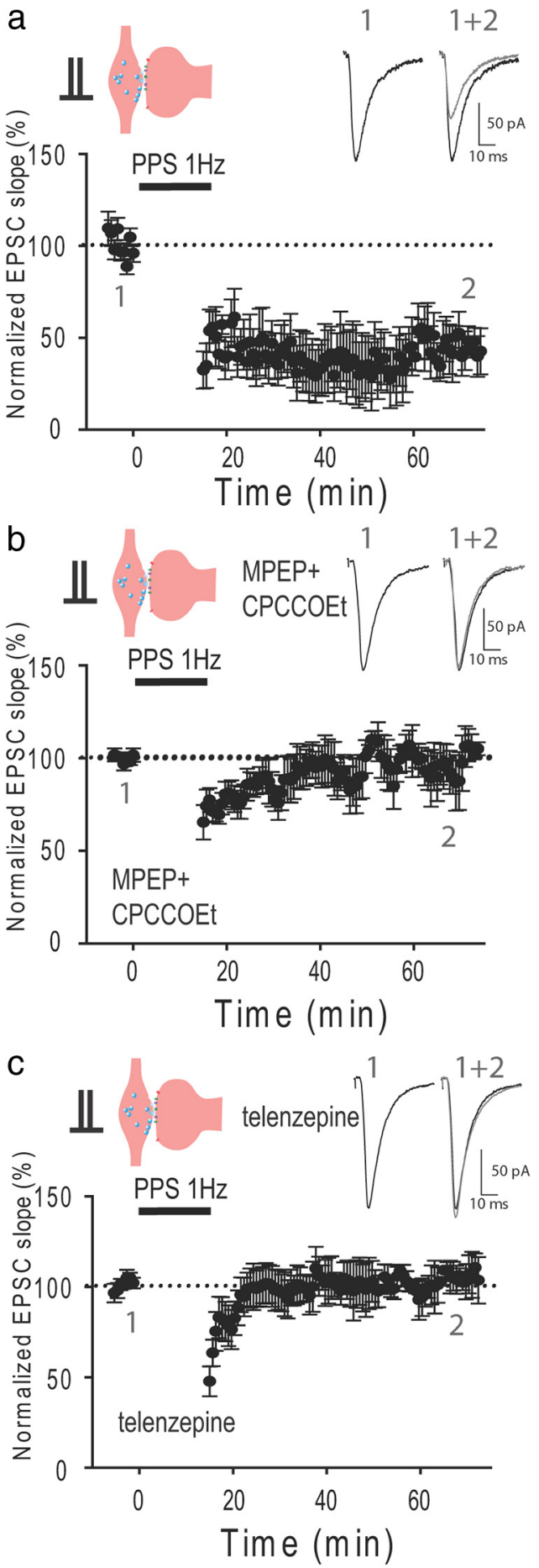

Figure 8. Train of paired-pulse stimulations is sufficient to induce LTD at mature TC synapses. $\boldsymbol{a}$, PPS (1 Hz, 900 pairs of stimuli) induces LTD at mature TC synapses. $\boldsymbol{b}$, PPS-LTD is blocked in the presence of MPEP and CPCCOEt. c, PPS-LTD is blocked in the presence of telenzepine. The insets show representative EPSCS (averaged from 5 traces) recorded before (1) and after (2) induction of LTD.

aptic group I mGluRs by sustained release of glutamate, produce TC LTD.

$M_{1}$ muscarinic activation unmasks LTD at mature TC synapses through downregulation of adenosine-dependent mechanisms

FM 1-43 experiments demonstrated that, during a $1 \mathrm{~Hz}$ train of thalamic stimulation, neurotransmitter release at mature tha- lamic afferents is enhanced by activation of $\mathrm{M}_{1} \mathrm{Rs}$ and that these mechanisms may underlie presynaptic gating of LTD at mature TC synapses. However, this $\mathrm{M}_{1} \mathrm{R}$-mediated increase in presynaptic function can be detected only after 2 min of continuous $1 \mathrm{~Hz}$ synaptic stimulation. This activity-dependent enhancement of presynaptic function suggests that sustained synaptic stimulation of thalamic afferents causes the release of a cofactor with glutamate that negatively affects glutamate release. It also suggests that activation of presynaptic $M_{1}$ Rs modulates the action of this cofactor on presynaptic function. One candidate for this cofactor is adenosine, which is released from presynaptic terminals in an activity-dependent manner (Grover and Teyler, 1993; Mitchell et al., 1993; Yawo and Chuhma, 1993; Manzoni et al., 1994) and acts presynaptically by decreasing neurotransmitter release at excitatory synapses through activation of $\mathrm{A}_{1} \mathrm{Rs}$ (Dunwiddie and Masino, 2001). In addition, several groups have reported negative cross talk between muscarinic receptors and $A_{1}$ Rs at presynaptic terminals (Worley et al., 1987; Bouron and Reuter, 1997; Oliveira et al., 2009). We therefore tested the hypothesis that the release of presynaptic gating during TC LTD involves the adenosine- $A_{1} R$ pathway.

We found that the single-pulse induction protocol (900 pulses at $1 \mathrm{~Hz})$ was sufficient to induce LTD $(45.9 \pm 11.2 \%$ of baseline; $p=0.012 ; 4$ of 4 neurons) at mature TC synapses when $A_{1} R$ was blocked with 8-cyclopentyl-1,3-dipropylxanthine (DPCPX) (1 $\mu \mathrm{M}$ ) (Fig. 9a). Likewise, the single-pulse induction protocol alone readily induced LTD at mature TC synapses of mice lacking $A_{1}$ Rs (38.9 $\pm 7.9 \%$ of baseline; $p<0.001 ; 5$ of 5 neurons) (Fig. $9 b$ ). LTD was also induced with this protocol (47.5 $\pm 9.4 \%$ of baseline; $p=0.007 ; 5$ of 5 neurons) in the presence of $\alpha \beta$-mADP (100 $\mu \mathrm{M})$, an inhibitor of ecto- $5^{\prime}$-nucleotidase, the enzyme that produces adenosine (Fig. 9c). These data indicate that blockade of the adenosine $-\mathrm{A}_{1} \mathrm{R}$ pathway is sufficient to release LTD gating at mature TC synapses. MPEP and CPCCOEt blocked this form of LTD ( $100.4 \pm 11.6 \%$ of baseline; $p=0.81 ; 0$ of 6 neurons), indicating that it is expressed through the same postsynaptic group I mGluR-dependent mechanisms as pairing-LTD, TGULTD, and PPS-LTD (Fig. 9d). Thus, these results demonstrate that either activation of $M_{1}$ Rs or inhibition of the adenosine $-A_{1} R$ pathway is sufficient to release a presynaptic gate that prevents the expression of LTD at mature TC synapses. To test whether these two mechanisms are within the same pathway, we performed occlusion experiments in which we sequentially induced pairing-LTD and LTD in the presence of DPCPX. We hypothesized that LTD will be enhanced after sequential induction of pairing-LTD and $A_{1} R$-dependent LTD if the adenosine- $A_{1} R$ and $M_{1} R$-gating mechanisms operate through different pathways or that LTD will be occluded if these mechanism are within the same pathway. We first showed that pairing-LTD saturates after the first round of induction (data not shown). We then found that LTD in the presence of DPCPX was occluded by pairingLTD (Fig. 9e), indicating that $\mathrm{M}_{1}$ Rs and the adenosine $-\mathrm{A}_{1} \mathrm{R}$ machinery operate within the same pathway that gates LTD at mature TC synapses. Although the pairing protocol reduced EPSCs to $55.9 \pm 5.1 \%$ of baseline ( $p<0.001 ; 6$ of 6 neurons), subsequent $1 \mathrm{~Hz}$ stimulation in the presence of DPCPX failed to further depress EPSCs $(62.0 \pm 5.6 \%$ of initial baseline; $p=$ $0.567 ; 0$ of 6 neurons). We reinforced our conclusion with the reverse experiment. We found that pairing-LTD was occluded by LTD induced in the presence of DPCPX (Fig. $9 f$ ). Although EPSCs were depressed to $58.9 \pm 9.3 \%$ of baseline $(p=0.024$; 5 of 6 neurons) after $1 \mathrm{~Hz}$ synaptic stimulation in the presence of DPCPX, a subsequent pairing protocol did not depress 

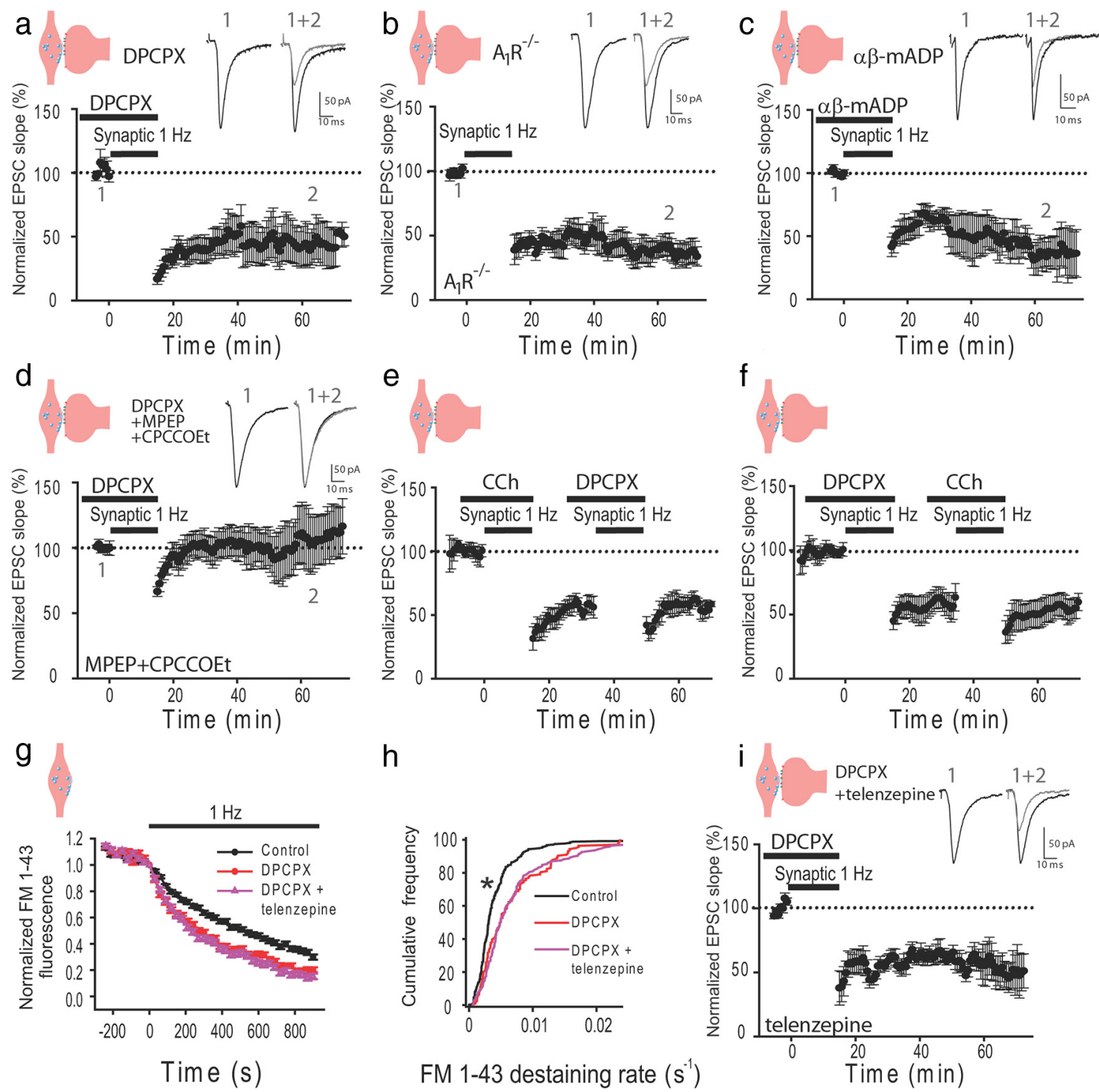

$\mathrm{h}$
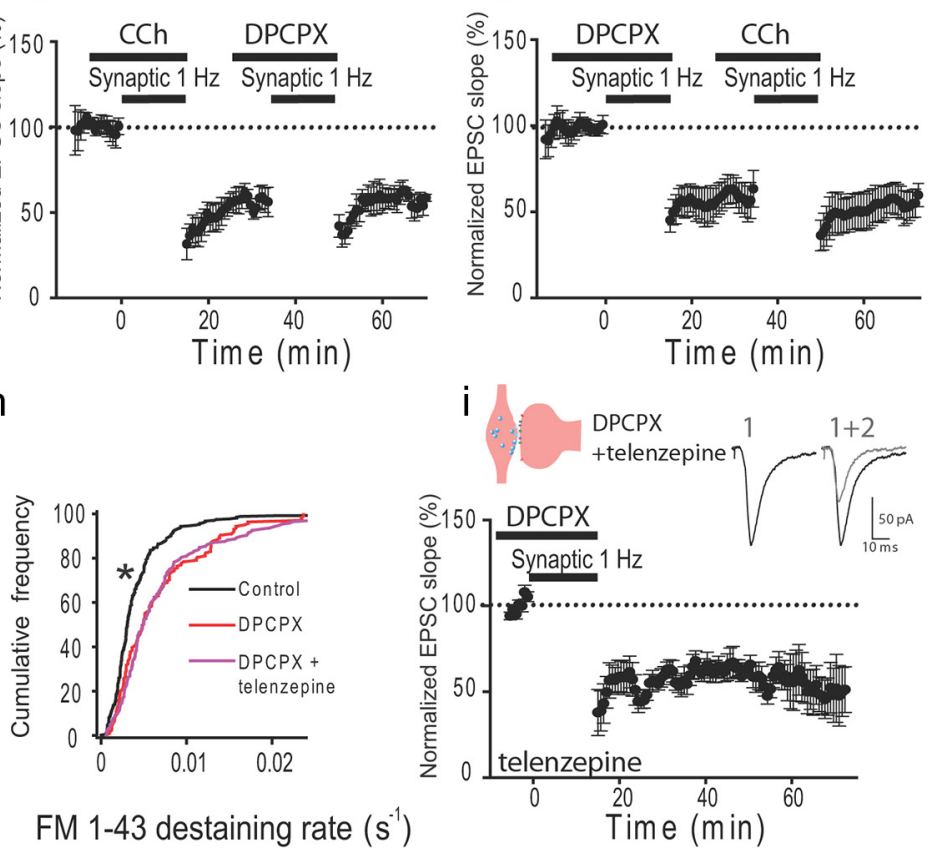

Figure 9. Inhibition of the adenosine- $A_{1} R$ pathways unmasks LTD at mature TC synapses. $\boldsymbol{a}-\boldsymbol{c}$, TCLTD is induced by a train of thalamic stimulation in the presence of DPCPX $(1 \mu \mathrm{m})(\boldsymbol{a})$, in $\mathrm{A}_{1} \mathrm{R}^{-/-}$mice $(\boldsymbol{b})$, or in the presence of $\alpha \beta$-mADP $(100 \mu \mathrm{m})(\boldsymbol{c})$. $\boldsymbol{d}$, Synaptic TC LTD induced in the presence of DPCPX is blocked by a mixture of group I mGluR blockers MPEP and CPCCOEt. $\boldsymbol{e}$, TC LTD in the presence of DPCPX is occluded by previous induction of pairing-LTD. $\boldsymbol{f}$, Pairing-LTD is occluded at mature TC synapses by previous induction of TC LTD in the presence of DPCPX. $\boldsymbol{g}, \boldsymbol{h}$, FM 1-43 destaining curves $(\boldsymbol{g})$ and cumulative histograms of destaining rates $(\boldsymbol{h})$ for thalamic boutons in control slices, slices treated with DPCPX, or those treated with DPCPX and telenzepine (175-285 boutons). ${ }^{*} p<0.001 . i$, Synaptic TCLTD induced in the presence of DPCPX is not blocked by telenzepine. The insets show representative EPSCS (averaged from 5 traces) recorded before (1) and after (2) induction of LTD.

EPSCs further $(54.5 \pm 8.4 \%$ of initial baseline; $p=0.44 ; 1$ of 6 neurons).

Next, we sought to determine the relationship between $\mathrm{M}_{1}$ Rs and the adenosine- $\mathrm{A}_{1} \mathrm{R}$ machinery in the presynaptic gating of TC LTD. We reasoned that inhibition of $M_{1}$ Rs will be ineffective at blocking the LTD induced by $A_{1} R$ inhibition if the adenosine $-A_{1} R$ machinery operates downstream of $M_{1} R$ activation. Alternatively, if the adenosine $-A_{1} R$ machinery operates upstream of $M_{1} R s$, then $M_{1} R$ inhibitors will block LTD induced by $\mathrm{A}_{1} \mathrm{R}$ inhibition. We tested these alternatives using the FM 1-43 assay and LTD in the presence of both DPCPX and telenzepine. First, we found that DPCPX increases neurotransmitter release at thalamic terminals (Fig. $9 g$ ). Second, telenzepine was ineffective at blocking the DPCPX-mediated increase in neurotransmitter release (Fig. 9g,h). The rates of FM 1-43 destaining in the presence of DPCPX and telenzepine $\left(0.00404 \pm 0.00041 \mathrm{~s}^{-1}\right.$; 7 slices, 12-92 boutons per slice) were not significantly different from that in the presence of only DPCPX $\left(0.00442 \pm 0.00072 \mathrm{~s}^{-1} ; 6\right.$ slices, $11-51$ boutons per slice; $p=0.646)$. However, these rates were substantially faster than those of control slices $(0.00245 \pm 0.00018$ $\mathrm{s}^{-1} ; 5$ slices, $26-86$ boutons per slice; $\left.p=0.013\right)$. These results suggested that the adenosine- $\mathrm{A}_{1} \mathrm{R}$ machinery operates downstream of $M_{1}$ Rs to presynaptically gate TC LTD. To test this hypothesis directly, we induced TC LTD by using a single-pulse protocol in the presence of $A_{1} R$ and $M_{1} R$ inhibitors. LTD induced in the presence of DPCPX persisted in the presence of telenzepine $(54.6 \% \pm 9.1 \%$ of baseline; 4 of 5 neurons; $p=0.008$ ) (Fig. 9i). Together, these results suggest that the activation of presynaptic $M_{1}$ Rs downregulates the adenosine $-\mathrm{A}_{1} \mathrm{R}$ machinery and thereby relieves presynaptic gating of LTD at mature TC synapses. Once the presynaptic gating is relieved and glutamate release can be maintained during prolonged stimulation, TC synapses express LTD through postsynaptic mechanisms that depend on group I mGluRs (Fig. 10).

\section{Discussion}

Neural circuits are highly susceptible to outside influences early in life. The formation of RFs in the ACx is governed by acoustic 


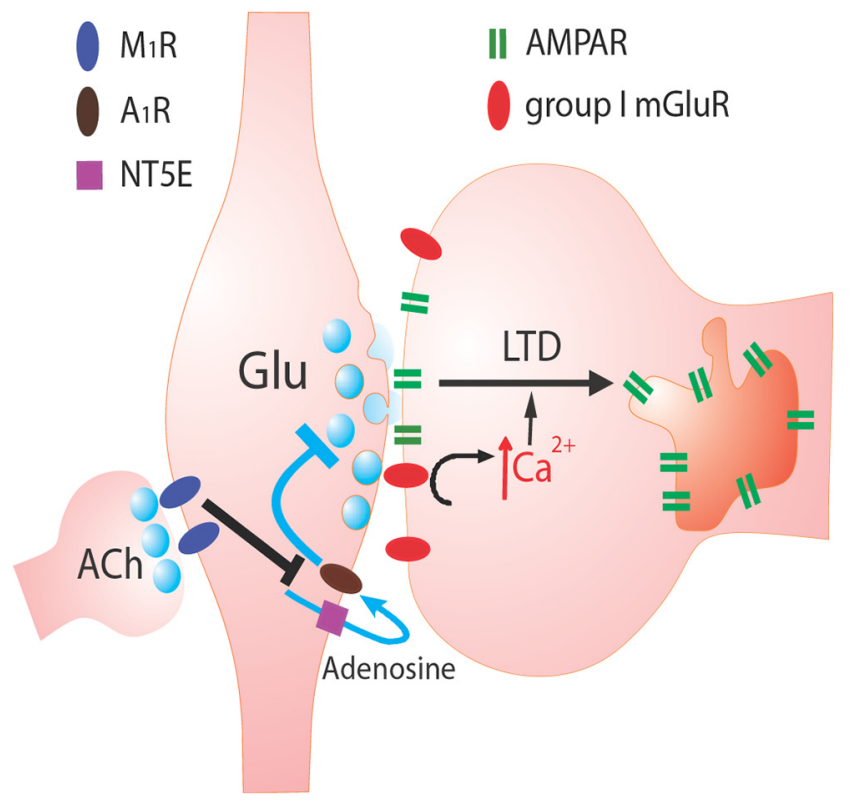

Figure 10. Model of presynaptic gating of postsynaptically expressed mGluR-dependent LTD at mature TC synapses. LTD is expressed postsynaptically through mGluR-dependent mechanisms only when presynaptic gating is released and prolonged presynaptic activation produces a sufficient amount of glutamate at TC synapses. Presynaptic gating can be released when presynaptic $M_{1} R$ s are activated and the autocrine adenosine $-A_{1} R$ machinery is downregulated.

experience during the early neonatal period; at that time, cortical networks are especially plastic (Katz and Shatz, 1996; Zhang et al., 2001; Chang and Merzenich, 2003; Hensch, 2005; de VillersSidani et al., 2007; Dorrn et al., 2010). This sensitivity to sensory activity early in life is believed to be crucial for children to develop stable representations of the auditory world (Doupe and Kuhl, 1999; Tallal and Benasich, 2002; Dorrn et al., 2010). Upon maturation, these cortical networks become less plastic in response to passive acoustic activity but undergo plastic changes if acoustic activity becomes behaviorally relevant or paired with the activation of cholinergic inputs (Bakin and Weinberger, 1996; Kilgard and Merzenich, 1998a; Weinberger, 2004, 2007b; Ma and Suga, 2005; Froemke et al., 2007; Keuroghlian and Knudsen, 2007). Here, we have shown that TC synapses may account for these properties of RF plasticity in the ACx. We have shown that, in brain slices containing the auditory thalamus and $\mathrm{ACx}$, synaptic plasticity at TC synapses is not lost upon maturation, but rather mature TC synapses acquire gating mechanisms that are released if cholinergic receptors are activated. Thus, the properties of long-term synaptic plasticity at mature TC inputs in the ACx in brain slices resemble those of RF plasticity in vivo. This finding implicates synaptic plasticity at TC inputs as a cellular substrate of RF plasticity in the ACx and creates opportunities to address new questions regarding the cellular and molecular mechanisms of sensory memory in vitro.

In this paper, we unmasked LTD at mature TC synapses and sought to elucidate mechanisms of its expression and gating. Because we identified this form of synaptic plasticity at mature TC synapses, here we propose that the previously observed critical period for synaptic plasticity described at TC synapses is not due to the actual loss of plastic mechanisms at these synapses but rather to the development of gating mechanisms that limit sustained release of glutamate from thalamic afferents. The absence of a critical period for anatomical changes of thalamic afferents was also recently proposed in the somatosensory cortex (Wim- mer et al., 2010). Using two-photon glutamate uncaging at individual thalamic inputs, we determined that LTD at mature TC synapses is expressed postsynaptically and requires an increase in the intracellular calcium in postsynaptic neurons via activation of postsynaptic group I mGluRs. This form of synaptic plasticity can be also induced at these synapses by using synaptic stimulation if it is paired with the activation of $M_{1}$ Rs. Thus, we concluded that $M_{1}$ Rs are involved in gating of LTD at mature TC synapses. Because the muscarinic antagonist blocked pairing-LTD but not TGU-LTD, we concluded that $\mathrm{M}_{1} \mathrm{R}$-dependent gating of LTD occurs presynaptically. The FM 1-43 assay confirmed that activation of $M_{1}$ Rs enhances a sustained neurotransmitter release in thalamic presynaptic boutons.

Using direct measures of presynaptic and postsynaptic function at individual synapses, we determined that group I mGluRs and $M_{1}$ Rs operate at different cellular loci to produce TC LTD: group I mGluRs are responsible for expression of LTD at the postsynaptic site and $M_{1}$ Rs presynaptically gate induction of this form of synaptic plasticity. Although these receptors operate at different cellular loci, inhibition of either one leads to the blockade of TC LTD. Requirements of $M_{1}$ Rs and mGluRs have been shown at other synapses by using electrophysiological techniques such as measurements of the PPRs of postsynaptic responses (Volk et al., 2007; Kamsler et al., 2010). However, that approach is less sensitive than TGU and the FM 1-43 assay in distinguishing between contributions of postsynaptic and presynaptic loci in synaptic plasticity (Blundon and Zakharenko, 2008). In contrast to TGU and FM 1-43 assays, PPR measurements also cannot distinguish changes that occur at postsynaptic or presynaptic sites during sustained activity such as that required for LTD induction.

Although previous reports have demonstrated a permissive role of $M_{1}$ Rs in TC LTD (Kirkwood et al., 1999; Choi et al., 2005), the cellular locus of their operation during LTD and their relationship to mGluRs has remained controversial. For instance, one group reported that mGluR-dependent LTD is blocked by $\mathrm{M}_{1} \mathrm{R}$ antagonists, and LTD produced by muscarinic agonists occludes mGluR-dependent LTD in the hippocampus (Volk et al., 2007). Because $M_{1}$ Rs and group I mGluRs both activate similar intracellular machinery that involves activation of protein kinase C via a q-type G-protein-coupled cascade (Oliet et al., 1997; Hasselmo, 1999; Malenka and Bear, 2004), those investigators concluded that group I mGluR-dependent mechanisms and $\mathrm{M}_{1} \mathrm{R}$-dependent mechanisms converge in the postsynaptic locus to produce LTD. Another group performed electrophysiological characterization of LTD in mutant mice lacking $M_{1}$ Rs in presynaptic CA3 hippocampal neurons and concluded that $\mathrm{M}_{1}$ Rs and group I mGluRs may be needed in the presynaptic locus to produce mGluR-dependent LTD at CA3-CA1 synapses (Kamsler et al., 2010). Using TGU, which bypasses neurotransmitter release and therefore is a direct indicator of postsynaptic function, we showed that mGluR-dependent LTD at mature TC synapses is expressed postsynaptically. Using the FM 1-43 assay, a direct indicator of presynaptic function, we also showed that $M_{1}$ Rs do not operate postsynaptically but rather gate mGluR-dependent LTD at the presynaptic locus through the downregulation of the adenosine machinery, which in turn leads to a more sustained neurotransmitter release during LTD induction at thalamic afferents.

Previous electrophysiological data were inconclusive about the presence of mGluRs at thalamocortical synapses. Lee and Sherman (2008) reported that a high-frequency train of thalamic stimulation failed to produce a postsynaptic response in layer IV neurons of somatosensory and ACx in the presence of ionotropic 
glutamate and GABA receptor blockers. However, mGluR blockers effectively inhibited TC EPSCs in the somatosensory cortex (Mateo and Porter, 2007). Here, we show that mGluR antagonists completely block TC LTD induced by four different experimental approaches: pairing of a prolonged thalamic stimulation with activation of $M_{1}$ Rs or inhibition of $A_{1} R s$, a train of paired-pulse thalamic stimulation, and two-photon uncaging at a single TC synapse. Thus, these experiments provide strong evidence that group I mGluRs are not only present at TC synapses but also important for postsynaptic mechanisms of TC LTD.

Several mechanisms have been proposed to contribute to the closing of the critical period for synaptic plasticity in sensory cortices (Daw et al., 1992; Foeller and Feldman, 2004; Hirata and Castro-Alamancos, 2006; Morishita et al., 2010). Among these are changes in NMDAR composition (Carmignoto and Vicini, 1992) and maturation of GABAergic inhibition (Kirkwood and Bear, 1994; Hensch et al., 1998), both of which occur during development. However, LTD that we unmasked at mature TC synapses neither required NMDARs nor was influenced by the inhibition of GABAergic transmission (Dudek and Friedlander, 1996). These results suggest that neither of these mechanisms regulates the critical period for TC LTD in the mature ACx. Activation of presynaptic $M_{1}$ Rs was sufficient to unmask TC LTD in slices from animals aged beyond the critical period, which is consistent with in vivo results showing that TC synapses remain plastic during adulthood (Heynen and Bear, 2001; Dringenberg et al., 2007) but require additional mechanisms for unmasking this plasticity.

How presynaptic $M_{1}$ Rs gate TC LTD is the focus of ongoing research. Activation of these receptors may lead to activation of protein kinase $\mathrm{C}$, which in turn may increase the probability of glutamate release (Malenka et al., 1986; Shapira et al., 1987). Alternatively, $M_{1}$ Rs may be involved in the generation of an autocrine cofactor that is released with glutamate from thalamic presynaptic terminals during LTD induction and positively regulates glutamate release. The third scenario may involve $M_{1} R s$ negatively regulating the release of a presynaptic cofactor that is a negative regulator of neurotransmitter release. The latter two scenarios are supported by the fact that cholinergic activation increases neurotransmitter release at TC synapses not before or at the initiation of LTD induction, but $\sim 2$ min after initiation of LTD induction. We are inclined to think that TC LTD is gated through the third scenario, in which adenosine, a negative regulator of neurotransmitter release, is coreleased with glutamate from thalamic afferents during induction of LTD. We showed that the effect of adenosine on presynaptic gating is mediated through $A_{1}$ Rs. Because $A_{1} R$ is a well known negative regulator of neurotransmitter release at excitatory glutamate synapses (Dunwiddie et al., 1981; Dunwiddie and Masino, 2001), we hypothesize that mature thalamic terminals release both glutamate and adenosine during synaptic stimulation, as was previously suggested for other neurotransmitters (Nicholls, 1995). Thus, prolonged synaptic stimulation that occurs during induction of LTD may gradually accumulate adenosine and thereby progressively inhibit glutamate release at the same synapse in an activitydependent manner. Consistent with this hypothesis, inhibition or deletion of $A_{1}$ Rs or inhibition of adenosine production is sufficient to release this presynaptic gate and enable group I mGluRdependent LTD at mature TC synapses.

We also hypothesized that activation of $M_{1}$ Rs negatively regulates the adenosine $-\mathrm{A}_{1} \mathrm{R}$ machinery at thalamic presynaptic terminals. Through this double-negative regulation, activation of $\mathrm{M}_{1}$ Rs increases neurotransmitter release during prolonged syn- aptic activity that occurs during the induction of LTD. The exact mechanisms by which $M_{1}$ Rs regulate the adenosine- $A_{1} R$ machinery is not clear. It remains to be seen whether $M_{1} R$ activation leads to decreased adenosine production or downregulation of $A_{1} R s$ in the presynaptic terminals. Regardless of the nature of molecular mechanisms that connect $\mathrm{M}_{1}$ Rs to TC LTD, here we present evidence that the activation of these receptors increases sustainability of neurotransmitter release from thalamic afferents during LTD induction, and that this is sufficient to unmask postsynaptically expressed mGluR-dependent LTD at mature TC synapses.

Recent reports have indicated that, although TC axons are thought to comprise one of the most powerful projections in the brain (Stratford et al., 1996; Gil et al., 1999), individual TC synapses are weak (Bruno and Sakmann, 2006) and respond to synaptic stimulation with low fidelity (Richardson et al., 2009). Thus, increased neurotransmitter release due to $M_{1} R$ activation may increase sustained synaptic transmission during $1 \mathrm{~Hz}$ induction of LTD, and this train of prolonged glutamate release may be sufficient to activate postsynaptic mGluRs to an extent that leads to successful expression of LTD at mature TC synapses. Without activation of $\mathrm{M}_{1}$ Rs, low fidelity of synaptic transmission and progressive depression of TC synaptic transmission during LTD induction may lead to insufficient neurotransmitter release, insufficient activation of mGluRs, and thus the failure to express LTD. This idea is consistent with the ability of a train of glutamate uncaging pulses to induce LTD at individual thalamic inputs. By design, the fidelity and sustainability of glutamate release is maximal during a train of two-photon glutamate uncaging; therefore, the induction of LTD via TGU alone is sufficient to express LTD at mature TC synapses.

The ability of an animal to adjust its behavior in response to constantly changing environmental stimuli is adaptive, as it enables improved behavioral performance in sensory-guided tasks. Neurons of the primary ACx can shift their frequency responses toward behaviorally important acoustic frequencies and away from other acoustic frequencies. These bidirectional shifts in RF tuning occur simply with passive tone exposure in young animals but require attention (which includes association with reward or punishment) in adult animals. The ability of young animals to shift RF tuning in the absence of associative cues corresponds to the ease at which TC synaptic plasticity can be expressed in the absence of any modulatory inputs, requiring only thalamic stimulation. Conversely, the added requirement of associative cues during the auditory training of adult animals parallels the appearance of an ACh-dependent gating mechanism that must first be released before TC synaptic plasticity is expressed.

An added synaptic plasticity requirement of modulatory inputs in mature animals may be viewed as overly restrictive and even maladaptive. However, the expression of a neuromodulatory gate that links sensory learning to associative cues in adults allows for increased behavioral performance that is specific to nonrandom sensory cues that are relevant and reinforced. ACh may be released at the time of sensory experience if that experience triggers attention or recognition from top-down brain circuits such as the associative ACx or prefrontal cortex. Both of these circuits project to cholinergic neurons of the nucleus basalis (Fritz et al., 2007), which then project directly to the primary ACx. Reward or punishment feedback cues following the behavioral response to sensory input also result in ACh release to the primary ACx via limbic system cascades to the nucleus basalis (Weinberger, 2007a). Thus, the presence of elevated levels of synaptic ACh may occur with every stimulus that is either novel, 
recognized, or reinforced, and may serve to either enhance TC synaptic connections relaying highly repeated stimuli or to depress less active sensory input connections. These bidirectional changes in synaptic strength may underlie bidirectional changes in RFs observed during learning. This also implies that mature TC synapses may undergo not only LTD described here but also long-term potentiation. Future experiments will show if releasing presynaptic gating is sufficient to express long-term potentiation at mature TC synapses.

In conclusion, our data suggest that, in auditory brain slice preparations, TC synapses do not lose their synaptic plasticity upon maturation but rather acquire gating mechanisms that lessen the sustained neurotransmitter release from thalamic afferents. Activation of presynaptic $M_{1} R s$ relieves this gating and maintains sustained neurotransmitter release at thalamic terminals during LTD induction, thereby allowing mature TC synapses to express mGluR-dependent LTD postsynaptically. Because gating properties of TC synaptic plasticity closely resemble those of RF plasticity recorded in the ACx in vivo, we propose that plastic changes at TC synapses may be a cellular substrate of experiencedependent RF plasticity in sensory cortices.

\section{References}

Bakin JS, Weinberger NM (1996) Induction of a physiological memory in the cerebral cortex by stimulation of the nucleus basalis. Proc Natl Acad Sci U S A 93:11219-11224.

Beierlein M, Connors BW (2002) Short-term dynamics of thalamocortical and intracortical synapses onto layer 6 neurons in neocortex. J Neurophysiol 88:1924-1932.

Blundon JA, Zakharenko SS (2008) Dissecting the components of longterm potentiation. Neuroscientist 14:598-608.

Bouron A, Reuter H (1997) Muscarinic stimulation of synaptic activity by protein kinase $\mathrm{C}$ is inhibited by adenosine in cultured hippocampal neurons. Proc Natl Acad Sci U S A 94:12224-12229.

Bruno RM, Sakmann B (2006) Cortex is driven by weak but synchronously active thalamocortical synapses. Science 312:1622-1627.

Buonomano DV, Merzenich MM (1998) Cortical plasticity: from synapses to maps. Annu Rev Neurosci 21:149-186.

Carmignoto G, Vicini S (1992) Activity-dependent decrease in NMDA receptor responses during development of the visual cortex. Science 258:1007-1011.

Chang EF, Merzenich MM (2003) Environmental noise retards auditory cortical development. Science 300:498-502.

Choi SY, Chang J, Jiang B, Seol GH, Min SS, Han JS, Shin HS, Gallagher M, Kirkwood A (2005) Multiple receptors coupled to phospholipase C gate long-term depression in visual cortex. J Neurosci 25:11433-11443.

Cole AE, Nicoll RA (1983) Acetylcholine mediates a slow synaptic potential in hippocampal pyramidal cells. Science 221:1299-1301.

Collingridge GL, Peineau S, Howland JG, Wang YT (2010) Long-term depression in the CNS. Nat Rev Neurosci 11:459-473.

Crair MC, Malenka RC (1995) A critical period for long-term potentiation at thalamocortical synapses. Nature 375:325-328.

Cruikshank SJ, Rose HJ, Metherate R (2002) Auditory thalamocortical synaptic transmission in vitro. J Neurophysiol 87:361-384.

Daw MI, Scott HL, Isaac JT (2007) Developmental synaptic plasticity at the thalamocortical input to barrel cortex: mechanisms and roles. Mol Cell Neurosci 34:493-502.

Daw NW, Fox K, Sato H, Czepita D (1992) Critical period for monocular deprivation in the cat visual cortex. J Neurophysiol 67:197-202.

de Villers-Sidani E, Chang EF, Bao S, Merzenich MM (2007) Critical period window for spectral tuning defined in the primary auditory cortex (A1) in the rat. J Neurosci 27:180-189.

Dodt HU, Eder M, Schierloh A, Zieglgänsberger W (2002) Infrared-guided laser stimulation of neurons in brain slices. Sci STKE 2002:pl2.

Dorrn AL, Yuan K, Barker AJ, Schreiner CE, Froemke RC (2010) Developmental sensory experience balances cortical excitation and inhibition. Nature 465:932-936.

Doupe AJ, Kuhl PK (1999) Birdsong and human speech: common themes and mechanisms. Annu Rev Neurosci 22:567-631.
Dringenberg HC, Hamze B, Wilson A, Speechley W, Kuo MC (2007) Heterosynaptic facilitation of in vivo thalamocortical long-term potentiation in the adult rat visual cortex by acetylcholine. Cereb Cortex 17:839-848.

Dudek SM, Friedlander MJ (1996) Developmental down-regulation of LTD in cortical layer IV and its independence of modulation by inhibition. Neuron 16:1097-1106.

Dunwiddie TV, Masino SA (2001) The role and regulation of adenosine in the central nervous system. Annu Rev Neurosci 24:31-55.

Dunwiddie TV, Hoffer BJ, Fredholm BB (1981) Alkylxanthines elevate hippocampal excitability. Evidence for a role of endogenous adenosine. Naunyn Schmiedebergs Arch Pharmacol 316:326-330.

Earls LR, Bayazitov IT, Fricke RG, Berry RB, Illingworth E, Mittleman G, Zakharenko SS (2010) Dysregulation of presynaptic calcium and synaptic plasticity in a mouse model of 22q11 deletion syndrome. J Neurosci 30:15843-15855.

Feldman DE, Brecht M (2005) Map plasticity in somatosensory cortex. Science 310:810-815.

Feldman DE, Nicoll RA, Malenka RC, Isaac JT (1998) Long-term depression at thalamocortical synapses in developing rat somatosensory cortex. Neuron 21:347-357.

Feldman DE, Nicoll RA, Malenka RC (1999) Synaptic plasticity at thalamocortical synapses in developing rat somatosensory cortex: LTP, LTD, and silent synapses. J Neurobiol 41:92-101.

Feldman ML, Peters A (1978) The forms of non-pyramidal neurons in the visual cortex of the rat. J Comp Neurol 179:761-793.

Foeller E, Feldman DE (2004) Synaptic basis for developmental plasticity in somatosensory cortex. Curr Opin Neurobiol 14:89-95.

Fox K (2002) Anatomical pathways and molecular mechanisms for plasticity in the barrel cortex. Neuroscience 111:799-814.

Fritz JB, Elhilali M, David SV, Shamma SA (2007) Does attention play a role in dynamic receptive field adaptation to changing acoustic salience in A1? Hear Res 229:186-203.

Froemke RC, Merzenich MM, Schreiner CE (2007) A synaptic memory trace for cortical receptive field plasticity. Nature 450:425-429.

Gil Z, Connors BW, Amitai Y (1999) Efficacy of thalamocortical and intracortical synaptic connections: quanta, innervation, and reliability. Neuron 23:385-397.

Gilbert CD (1998) Adult cortical dynamics. Physiol Rev 78:467-485.

Grover LM, Teyler TJ (1993) Role of adenosine in heterosynaptic, posttetanic depression in area CA1 of hippocampus. Neurosci Lett 154:39-42.

Hasselmo ME (1999) Neuromodulation: acetylcholine and memory consolidation. Trends Cogn Sci 3:351-359.

Hensch TK (2005) Critical period plasticity in local cortical circuits. Nat Rev Neurosci 6:877-888.

Hensch TK, Fagiolini M, Mataga N, Stryker MP, Baekkeskov S, Kash SF (1998) Local GABA circuit control of experience-dependent plasticity in developing visual cortex. Science 282:1504-1508.

Heynen AJ, Bear MF (2001) Long-term potentiation of thalamocortical transmission in the adult visual cortex in vivo. J Neurosci 21:9801-9813.

Hirata A, Castro-Alamancos MA (2006) Relief of synaptic depression produces long-term enhancement in thalamocortical networks. J Neurophysiol 95:2479-2491.

Hubel DH, Wiesel TN (1970) The period of susceptibility to the physiological effects of unilateral eye closure in kittens. J Physiol 206:419-436.

Huber KM, Kayser MS, Bear MF (2000) Role for rapid dendritic protein synthesis in hippocampal mGluR-dependent long-term depression. Science 288:1254-1257.

Inomata N, Tokutomi N, Oyama Y, Akaike N (1988) Intracellular picrotoxin blocks pentobarbital-gated $\mathrm{Cl}^{-}$conductance. Neurosci Res 6: $72-75$.

Isaac JT, Crair MC, Nicoll RA, Malenka RC (1997) Silent synapses during development of thalamocortical inputs. Neuron 18:269-280.

Jiang B, Treviño M, Kirkwood A (2007) Sequential development of longterm potentiation and depression in different layers of the mouse visual cortex. J Neurosci 27:9648-9652.

Jo J, Son GH, Winters BL, Kim MJ, Whitcomb DJ, Dickinson BA, Lee YB, Futai K, Amici M, Sheng M, Collingridge GL, Cho K (2010) Muscarinic receptors induce LTD of NMDAR EPSCs via a mechanism involving hippocalcin, AP2 and PSD-95. Nat Neurosci 13:1216-1224.

Johansson B, Halldner L, Dunwiddie TV, Masino SA, Poelchen W, GiménezLlort L, Escorihuela RM, Fernández-Teruel A, Wiesenfeld-Hallin Z, Xu XJ, Hårdemark A, Betsholtz C, Herlenius E, Fredholm BB (2001) Hy- 
peralgesia, anxiety, and decreased hypoxic neuroprotection in mice lacking the adenosine A1 receptor. Proc Natl Acad Sci U S A 98:9407-9412.

Kamsler A, McHugh TJ, Gerber D, Huang SY, Tonegawa S (2010) Presynaptic $\mathrm{ml}$ muscarinic receptors are necessary for mGluR long-term depression in the hippocampus. Proc Natl Acad Sci U S A 107:1618-1623.

Katz LC, Shatz CJ (1996) Synaptic activity and the construction of cortical circuits. Science 274:1133-1138.

Kemp N, Bashir ZI (1999) Induction of LTD in the adult hippocampus by the synaptic activation of AMPA/kainate and metabotropic glutamate receptors. Neuropharmacology 38:495-504.

Kemp N, McQueen J, Faulkes S, Bashir ZI (2000) Different forms of LTD in the CA1 region of the hippocampus: role of age and stimulus protocol. Eur J Neurosci 12:360-366.

Keuroghlian AS, Knudsen EI (2007) Adaptive auditory plasticity in developing and adult animals. Prog Neurobiol 82:109-121.

Kilgard MP, Merzenich MM (1998a) Cortical map reorganization enabled by nucleus basalis activity. Science 279:1714-1718.

Kilgard MP, Merzenich MM (1998b) Plasticity of temporal information processing in the primary auditory cortex. Nat Neurosci 1:727-731.

Kirkwood A, Bear MF (1994) Hebbian synapses in visual cortex. J Neurosci 14:1634-1645.

Kirkwood A, Rozas C, Kirkwood J, Perez F, Bear MF (1999) Modulation of long-term synaptic depression in visual cortex by acetylcholine and norepinephrine. J Neurosci 19:1599-1609.

Lee CC, Sherman SM (2008) Synaptic properties of thalamic and intracortical inputs to layer 4 of the first- and higher-order cortical areas in the auditory and somatosensory systems. J Neurophysiol 100:317-326.

Liu BH, Wu GK, Arbuckle R, Tao HW, Zhang LI (2007) Defining cortical frequency tuning with recurrent excitatory circuitry. Nat Neurosci 10:1594-1600.

Lund JS (1973) Organization of neurons in the visual cortex, area 17, of the monkey (Macaca mulatta). J Comp Neurol 147:455-496.

Ma X, Suga N (2005) Long-term cortical plasticity evoked by electric stimulation and acetylcholine applied to the auditory cortex. Proc Natl Acad Sci U S A 102:9335-9340.

MacLean JN, Fenstermaker V, Watson BO, Yuste R (2006) A visual thalamocortical slice. Nat Methods 3:129-134.

Malenka RC, Bear MF (2004) LTP and LTD: an embarrassment of riches. Neuron 44:5-21.

Malenka RC, Madison DV, Nicoll RA (1986) Potentiation of synaptic transmission in the hippocampus by phorbol esters. Nature 321:175-177.

Manzoni OJ, Manabe T, Nicoll RA (1994) Release of adenosine by activation of NMDA receptors in the hippocampus. Science 265:2098-2101.

Mateo Z, Porter JT (2007) Group II metabotropic glutamate receptors inhibit glutamate release at thalamocortical synapses in the developing somatosensory cortex. Neuroscience 146:1062-1072.

Matsuzaki M, Ellis-Davies GC, Nemoto T, Miyashita Y, Iino M, Kasai H (2001) Dendritic spine geometry is critical for AMPA receptor expression in hippocampal CAl pyramidal neurons. Nat Neurosci 4:10861092.

Metherate R, Ashe JH (1993) Ionic flux contributions to neocortical slow waves and nucleus basalis-mediated activation: whole-cell recordings in vivo. J Neurosci 13:5312-5323.

Mitchell JB, Lupica CR, Dunwiddie TV (1993) Activity-dependent release of endogenous adenosine modulates synaptic responses in the rat hippocampus. J Neurosci 13:3439-3447.

Morishita H, Miwa JM, Heintz N, Hensch TK (2010) Lynx1, a cholinergic brake, limits plasticity in adult visual cortex. Science 330:1238-1240.

Nelson S, Toth L, Sheth B, Sur M (1994) Orientation selectivity of cortical neurons during intracellular blockade of inhibition. Science 265:774777.
Nicholls DG (1995) Proteins, transmitters and synapses. Oxford: Blackwell.

Oliet SH, Malenka RC, Nicoll RA (1997) Two distinct forms of long-term depression coexist in CAl hippocampal pyramidal cells. Neuron 18:969-982.

Oliveira L, Timóteo MA, Correia-de-Sá P (2009) Negative crosstalk between $M_{1}$ and $M_{2}$ muscarinic autoreceptors involves endogenous adenosine activating $A_{1}$ receptors at the rat motor endplate. Neurosci Lett 459:127-131.

Richardson RJ, Blundon JA, Bayazitov IT, Zakharenko SS (2009) Connectivity patterns revealed by mapping of active inputs on dendrites of thalamorecipient neurons in the auditory cortex. J Neurosci 29:64066417.

Rose HJ, Metherate R (2005) Auditory thalamocortical transmission is reliable and temporally precise. J Neurophysiol 94:2019-2030.

Shapira R, Silberberg SD, Ginsburg S, Rahamimoff R (1987) Activation of protein kinase $\mathrm{C}$ augments evoked transmitter release. Nature 325:58 -60.

Smith PH, Populin LC (2001) Fundamental differences between the thalamocortical recipient layers of the cat auditory and visual cortices. J Comp Neurol 436:508-519.

Stratford KJ, Tarczy-Hornoch K, Martin KA, Bannister NJ, Jack JJ (1996) Excitatory synaptic inputs to spiny stellate cells in cat visual cortex. Nature 382:258-261.

Tallal P, Benasich AA (2002) Developmental language learning impairments. Dev Psychopathol 14:559-579.

Volk LJ, Pfeiffer BE, Gibson JR, Huber KM (2007) Multiple Gq-coupled receptors converge on a common protein synthesis-dependent long-term depression that is affected in fragile $\mathrm{X}$ syndrome mental retardation. J Neurosci 27:11624-11634.

Weinberger NM (2004) Specific long-term memory traces in primary auditory cortex. Nat Rev Neurosci 5:279-290.

Weinberger NM (2007a) Associative representational plasticity in the auditory cortex: a synthesis of two disciplines. Learn Mem 14:1-16.

Weinberger NM (2007b) Auditory associative memory and representational plasticity in the primary auditory cortex. Hear Res 229:54-68.

Wimmer VC, Broser PJ, Kuner T, Bruno RM (2010) Experience-induced plasticity of thalamocortical axons in both juveniles and adults. J Comp Neurol 518:4629-4648.

Worley PF, Baraban JM, McCarren M, Snyder SH, Alger BE (1987) Cholinergic phosphatidylinositol modulation of inhibitory, $\mathrm{G}$ protein-linked neurotransmitter actions: electrophysiological studies in rat hippocampus. Proc Natl Acad Sci U S A 84:3467-3471.

Yawo H, Chuhma N (1993) Preferential inhibition of omega-conotoxinsensitive presynaptic $\mathrm{Ca}^{2+}$ channels by adenosine autoreceptors. Nature 365:256-258.

Yazaki-Sugiyama Y, Kang S, Câteau H, Fukai T, Hensch TK (2009) Bidirectional plasticity in fast-spiking GABA circuits by visual experience. Nature 462:218-221.

Zakharenko SS, Zablow L, Siegelbaum SA (2001) Visualization of changes in presynaptic function during long-term synaptic plasticity. Nat Neurosci 4:711-717.

Zakharenko SS, Zablow L, Siegelbaum SA (2002) Altered presynaptic vesicle release and cycling diring mGluR-dependent LTD. Neuron 35:1099-1110.

Zakharenko SS, Patterson SL, Dragatsis I, Zeitlin SO, Siegelbaum SA, Kandel ER, Morozov A (2003) Presynaptic BDNF required for a presynaptic but not postsynaptic component of LTP at hippocampal CA1-CA3 synapses. Neuron 39:975-990.

Zhang LI, Bao S, Merzenich MM (2001) Persistent and specific influences of early acoustic environments on primary auditory cortex. Nat Neurosci 4:1123-1130. 